LBL-36211

UC- 2000

RAC-5

\title{
Development of Hydrogeological Modelling Approaches for Assessment of Consequences of Hazardous Accidents at Nuclear Power Plants
}

Vyacheslav G. Rumynin, Valery A. Mironenko, Pavel K. Konosavsky, and Svetlana A. Pereverzeva

St. Petersburg Mining Institute

St. Petersburg, Russia

July 1994

Lawrence Berkeley Laboratory

University of California

Berkeley, California 94720

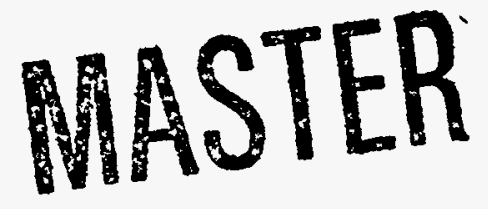

This work was supported by the U.S. Department of Energy, Office of Environmental Management, Office of Technology Development, and the Office of Energy Research, Office of Basic Energy Sciences, under Contract No. DE-AC03-76SF00098. 


\section{DISCLAIMER}

This report was prepared as an account of work sponsored by an agency of the United States Government. Neither the United States Government nor any agency thereof, nor any of their employees, make any warranty, express or implied, or assumes any legal liability or responsibility for the accuracy, completeness, or usefulness of any information, apparatus, product, or process disclosed, or represents that its use would not infringe privately owned rights. Reference herein to any specific commercial product, process, or service by trade name, trademark, manufacturer, or otherwise does not necessarily constitute or imply its endorsement, recommendation, or favoring by the United States Government or any agency thereof. The views and opinions of authors expressed herein do not necessarily state or reflect those of the United States Government or any agency thereof. 


\section{DISCLAIMER}

Portions of this document may be illegible in electronic image products. Images are produced from the best available original document. 


\begin{abstract}
This paper introduces some modelling approaches for predicting the influence of hazardous accidents at nuclear reactors on groundwater quality. Possible pathways for radioactive releases from nuclear power plants were considered to conceptualize boundary conditions for solving the subsurface radionuclides transport problems. Some approaches to incorporate physical-and-chemical interactions into transport simulators have been developed. The hydrogeological forecasts were based on numerical and semianalytical scale-dependent models. They have been applied to assess the possible impact of the nuclear power plants designed in Russia on groundwater reservoirs.
\end{abstract}




\section{Contents}

1. Introduction

2. Radionuclide release scenarios and how they affect the choice of RNT models

3. On numerical and-and-analytical solutions of mass-transport problems....................8

4. Simplified models for the RNT by colloids in fractured-porous groundwater reservoirs

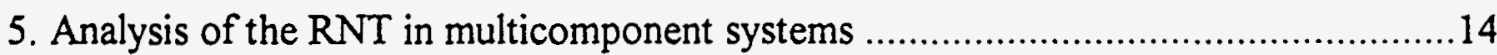

6. A simplified model for analysis of the infiltration type of groundwater pollution

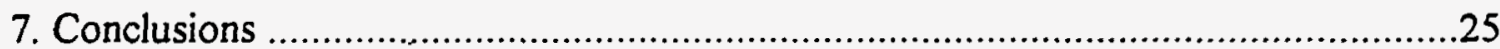

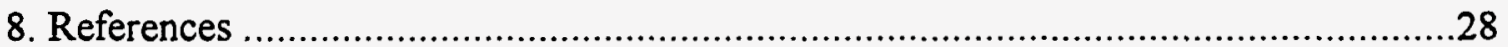

\section{Appendixes}

1. A short comment on "Kd-approach".

2. Some generalized solutions for mass-transport in fractured porous reservoirs

3. A brief overview of the performed hydrogeological assessment for hypothetical accidents at industrial and experimental nuclear reactors in Russia

4. Surface complexation 


\section{Introduction}

The Chernobyl disaster and a few other accidents occurred at nuclear reactors during the last decade sharply changed people's attitude towards the safety of the atomic energy policy. People realized that it is impossible to exclude completely the possibility of such accidents at nuclear power plants (NPP) which should be treated as a potential sources of extremely hazardous radioactive impact on the environment. This understanding served as starting point for developing the risk assessment analysis that deals with impacts which can cause low-probability but high-consequence hazards.

Under this condition soil and groundwater becomes one of the most vulnerable objects for radionuclides released from the failed reactors (Shestopalov and Gudzenko, 1993). This circumstance was underlined in special requirements (Hydrogeological Aspects...,1986) elaborated by the International Atomic Energy Agency (IAEA). Unfortunately these requirements and methodical recommendations for the impact assessments were written in a very uncertain and formal manner. Thus they do not take into account the real character of the radioactive release process and say almost nothing about intensity of the formed contaminant sources. Besides, the mathematical models recommended in the referred publications are rather formal and do not meet the moderm viewpoints on subsurface migration processes.

The study of the problem was stimulated by the necessity of carrying out ecological assessments for several NPP's projects in Russia. They are proposed to be located in the Cola Peninsula, the Far East and the St.-Petersburg Province. It means that different hydrogeological environment (such as porous, fractured and fractured-porous groundwater reservoirs) have been under consideration. Therefore different migration mechanisms and models need to be analysed and developed.

The above determines the priority in the field of risk assessment analysis (hydrogeological aspects) and we mobilized our research activities in the following directions: 
(a) evaluation of the possible pathways for radioactivity releases from nuclear reactors in order to show how scenarios of concern could be combined with the set of hydrogeological models;

(b) reexamination of the applicability of classical mathematical schemes for describing nuclear transport problems;

(c) assessment of possible industrial impacts on groundwater reservoirs within the influence area of new NPP designed in Russia.

\section{Radionuclide release scenarios and how they affect the choice of RNT models}

To analyse the relevant impact hazards, we must first characterize the paths of introducing the radionuclides into the underground hydrosphere. For this purpose we have to consider the possible scenarios of hazardous accidents at nuclear reactors resulting from the risk assessment theory.

The emergency situations described below refer to the events which are hardly probable, however their aftereffects can be of catastrophic character. Such events conform to the 5 or 6 levels of the IAEA scale, and they include also the postulated over- hazardous accidents potentially exceeding their ultimate level taken into accoint within the projects. The probability of such accidents at the nuclear reactor plants can be estimated to be less than $\cdot 10^{-7}$ per one reactor a year.

The basic data on the possible radioactive impact are quoted from the results of mathematical modelling of the overhazardous accidents at nuclear reactors of the last generation in Russia (WWR-1000 and W-407/block NP-500 types). The analyses of the failures after-effects enabled us to distinguish two quite different pathways for radiation release from the reactor protective shell (Table 1).

The first pathway of radiation release facilitates the formation of a local (point) source for groundwater contamination by radionuclides. Its occurrence is associated with a number of postulated accidents when heavy damage of active reactor zone takes place due to 
failure of the cooling system followed by a simultaneous malfunction of the equipment for failure localization. The long-term leakage of radioactive water (condensate or water from the emergency reservoir) could be a source of contamination for ground water. The potential radio-nuclide composition of wastes is rather variable (Rumynin V.G. et al., 1992), however, the analysis allows to detect four major isotopes extremely hazardous for ground water (Table 1).

The second pathway of radiation release facilitates the formation of an areal (nonpoint) source for ground water radioactive contamination, i.e. atmospheric precipitation followed by seepage through contaminated soils. The corresponding postulated scenarios assume also a damage or melting of the reactor active zone caused by failure of its cooling system, but without breaking of its protective shell. Radionuclides precipitation from the gas-aerosol mixture on the land surface occurs with the highest density, $P_{f}$ (Table 1).This level of radioactive contamination may be reached: a)within the range of $2.5 \mathrm{~km}$ around a NPP - in the case of a low emergency plume; b) within the range of $25-30 \mathrm{~km}$ in the case of a high emergency plume.

The hazardous accidents at the NPP described above lead to a very specific impact on the underground hydrosphere.This poses a question whether existing analytical or numerical methods and approaches are efficient enough to study the outlined class of tasks.

The first pathway of radioactive release forms a contaminant source with extremely high radionuclide concentrations $C_{\max }$ which exceed the safety standart by eight to ten orders of magnitude $C_{s s}$ (Table 1).This requires that the model assessments should be reliable enough to simulate concentration plumes where the ratio $C_{s s} / C_{\max }$ is some times less than $\cdot 10^{-10}$.The given limit is not easyly reached by applying the "classical" numerical methods. This, in particular, has been shown by Dougherly and Bagtroglou(1993). There are two major ways to improve the situation: (a) to use non-traditional and rather sophisticated digital algorithms and (b) to combine the existing algorithms with analytical techniques. In this paper we are following the latter (Section 3).

For the second pathway of radioactive release the overall model is to couple vertical transport through the unsaturated zone and subhorizontal (in the areal plane) transport 
Table 1. Parameters of radioactive contamination caused by hazardous accidents at AS

\begin{tabular}{|c|c|c|c|c|c|}
\hline \multirow{2}{*}{$\begin{array}{l}\text { Radio- } \\
\text { nuciide }\end{array}$} & \multicolumn{3}{|c|}{ The first pathway } & The second & Safety \\
\hline & $\begin{array}{c}\mathrm{C}_{0} \\
\mathrm{C} i \star I^{-1}\end{array}$ & $\begin{array}{l}\text { Qo } \\
1 \times h^{-1}\end{array}$ & $\begin{array}{c}t, \\
\text { month }\end{array}$ & $\begin{array}{c}\mathrm{P}_{\mathrm{f}} \\
\mathrm{C} i \star \mathrm{km}^{-2}\end{array}$ & $\mathrm{Ci} \times 1^{-1}$ \\
\hline$J-131$ & $14 / 14$ & $30 / 10$ & $24 / 1$ & $20000 /-$ & 2. $O E(-9)$ \\
\hline Cs-137 & $1.5 / 2.0$ & $30 / 10$ & $24 / 1$ & $1000 / 100$ & 1. $5 E(-8)$ \\
\hline $5 r-90$ & $0.3 / 0.2$ & $30 / 10$ & $24 / 1$ & $10 / 10$ & $4.1 E(-10)$ \\
\hline $\mathrm{Ce}-144$ & $0.3 /-$ & $30 / 10$ & $24 / 1$ & - & 1.2E $(-8)$ \\
\hline
\end{tabular}

Note:Enumerator - parameters for an accident at nuclear reactor "WWR-1000" (model of the Kola Research Centre); denominator - the parameters for an accident at the reactor (block) "W-407" (model of the institute "Atomenergoproject"); Co - radionuclide concentration in a condensate; $Q 0$ is the rate of leakage; $t$ is the duration of leakage; $\mathrm{Pf}$ is the density of the surface contamination derived from atmospheric radionuclide precipitation. 
in aquifers. The general solution of the problem is rather complex but can again be efficiently solved by combining numerical and analytical techniques (Section 6).

The key role in the RNT problem places the incorporation of hydrogeo-chemical interactions into the transport models. Two approaches are well-known and some times can be considered as fairly competitive. The first one is based on the so-called "Kd concept" (Appendix 1) and combines all kinds of heterogeneous chemical reactions in a single phenomenological coefficient of sorption distribution $K_{d}$. According to the second approach the interactions are reflected explicilty in the calculation schemes that imply using multicomponent models. Being more rigorous the multicomponent models however often are not available because of the lack of thermodynamic data for hetero geneous interactions. Therefore from a practical point of view the choice between the two mentioned approaches turns out to be far from trivial - see Section 5 .

Multidimensionality of the transport process and manifestation of heterogeneous properties of groundwater reservoirs affect the choice considerably.

\section{On numerical-and-analytical solutions of mass-transport problems}

It seems expedient to include analytical elements into the calculation procedures in orcier to take into consideration processes which place the most significant role in reducing the mass flux in porous or fractured media such as: (a) radioactive decay and (b) massexchange betweeen mobile and immobile water in heterogeneous reservoirs with double porosity e.g. in fractured-porous rocks.

The first approach is valid for analyzing linear processes. It is based on the representation of the final solution in an integral form (Appendix 2), where the concentration function $C^{\prime}(\theta)$ can be distinguished - as a numerical solution associated with nonreactive transport in equivalent homogeneous strata, and some analytical function $H_{0}(t, \theta)$ (or its derivative $\left.\partial H_{0}(t, \theta) / \partial \theta\right)$ which describes of radioactive decay and/or mass-exchange processes in heterogeneous aquifer (Rumynin, 1983): 


$$
C=\int_{0}^{t} \frac{\partial C^{\prime}(\theta)}{\partial \theta} H_{0}(t, \theta)
$$

Having integrated by parts the last expression (Lindstrom, 1976) we obtain:

$$
C=C^{\prime}(\theta) H_{0}(t, \theta)_{0}^{t}-\int_{0}^{t} C^{\prime}(\theta) \frac{\partial H_{0}(t, \theta)}{\partial \theta} d \theta,
$$

which is more suitable for the further recalculation of the model data.

In Appendix 2 one can find the basic representations for the $H_{0}(t, \theta)$ function and its derivat for the case of the RNT in fractured-porous reservoirs where the radioactive decay takes place.

The approach under consideration have been applied to simulation of the RNT taking place after the hypothetical hazardous accidents at NPP designed in Russia. The major results of the model assessment and practical conclusions are presented in Appendix 3.

According to the second approach an analytical sink-function $w_{s}$, responsible for massexchange and decay, is directly included into the finite-difference equations. Thus for the heterogeneous fractured-porous media equation (1) is valid, which describes diffusion of decayed species from water in the fractures into the porous matrix. In this case there is a possibility to study nonlinear processes as will be discussed in the next Section.

\section{Simplified models for the RNT by colloids in fractured-porous groundwater reservoirs}

The problem of RNT in groundwater in colloid form is widely debated nowadays. The colloids could be of natural origin associated with processes of rock weathering, or their formation may be due to the influence of radioactive contamination on the host rocks (Castaing, 1991; Torok et al., 1990). A significant importance of microbiological processes in colloid formation (King and Killoy, 1990) hampers their study under laboratory conditions. In natural water of deep horizons concentration of colloids (cores of which are very often represented by molecules of silicon acid or by clay particles) do not exceed several $\mathrm{mg} \cdot \mathrm{L}^{-1}$ (Vilks et al.,1992). In groundwater they can reach a few tens of $m g \cdot L^{-1}$ which is rather essential in comparison with the radionuclides concentrations. 
For understanding the role of colloid formation during radionuclide migration three aspects are of prime importance: 1) poor sorption of migrating elements in colloidal form by the mineral surfaces; 2) redistribution of substances between the sorptive fracture surfaces and migrating colloids in favour of the latter and 3) rather low diffusive permeability of micro- porous materials for colloidal particles; the latter aspect is of principal significance for the analysis of migration in fractured-porous strata.

In the simplest case colloid formation can be included into the model of mass-transport by the reaction of radionuclide adsorption $\left(M_{1}\right)$ on colloidal particles $\left(M_{2}\right)$ :

$$
M_{1}+M_{2}=M_{1} M_{2} \text {, }
$$

causing the formation of the compound $M_{1} M_{2}$. The equation (3) is conjugated with the standard equation of radionuclide adsorption by rocks.

Hence, the equilibrium relationships between concentrations of the substance in a solution $C_{1}, C_{2}, C_{12}$ and on rock $\bar{C}_{1}$ are governed by formulae of the following kind:

$$
\begin{aligned}
C_{12} & =K_{12} C_{1} C_{2}, \\
\bar{C}_{1} & =K_{1} C_{1} ;
\end{aligned}
$$

the coefficients of proportionality (of equilibrium) can be defined by the following obvious relationships:

$$
K_{12}=F K_{d}, K_{1}=\rho K_{d}
$$

where $K_{d}$ is the adsorption distribution coefficient, F - some coefficient of "strengthening" ( $F>>1)$, showing more strong colloid-nuclide interaction in comparison with sorption on the mineral framework of the rock (Vilks and Deguelare, 1991; Vilks et al.,1991).

By formulating the balance equation for the elementary stream tube, it is easy to obtain an expression which enables to control the degree of sorption retardation due to the presence of colloids in a solution:

$$
R=1+\frac{\rho K_{d}}{n\left(1+F K_{d} C_{1}\right)}
$$

It is obvious from the equation (7) that formation of the colloids becomes essential for the migration process when $F K_{d} C_{2}>0.2-0.5$. According to Vilks et al., 1991, the magnitude of 
$F K_{d}$ can reach the value of $N * 10^{4} \mathrm{~cm}^{3} \mathrm{~g}^{-1}$, i.e. the colloids transport plays a remarkable role in radionuclide migration for sufficiently high content of colloidal particles in ground water $\left(C_{2}>10 \mathrm{mg} \cdot \mathrm{L}^{-3}\right)$.

During migration in heterogeneous fractured-porous media the absorption of dissolved radionuclides by the porous matrix leads to the disturbance of initial equilibrium in the system as well as to the partial rejection of colloids. This process involves the overall area of transport and for its stringent mathematical description one should refer to the system of differential balance equations:

$$
\begin{aligned}
& n \frac{\partial C_{1}^{T}}{\partial t}+n \lambda C_{1}^{T}+\frac{\partial \bar{C}_{1}^{T}}{\partial}+\lambda \bar{C}_{1}+w_{s}=L\left(C_{1}^{T}\right), \\
& n \frac{\partial C_{2}^{T}}{\partial t}=L\left(C_{2}^{T}\right),
\end{aligned}
$$

where $C_{1}^{T}$ and $C_{2}^{T}$ are total concentrations $C_{1}^{T}=C_{1}+C_{12}, C_{2}^{T}=C_{2}+C_{12}, C_{12}=K_{12} C_{1} C_{2}$; $\mathrm{L}(\mathrm{z})$ - linear differential operator for convective-dispersive mass-transport; the function $w_{s}$ is defined in compliance with the expression (A.3) when $C=C_{1}$.

Nonlinear equations (8) can be easily transformed (Lewis et al., 1986) into a form convenient for numerical calculations by the method of finite differences. We have implemented a computer realisation of a corresponding algorithm for the one- dimensional version.

Particular results of the model assessments are depicted in Fig.1. Due to the presence of the colloid fraction in the moving solution the RNT potential is changed. It is important to under- line that in combination with the longitudinal hydrodinamic dispersion the colloidforming process leads to increasing concentration values at the advanced front of the concentration wave - in comparison with the case $K_{12}=0$. The relevant differences can reach one to two orders of magnitude (Fig.1). The effect is the more significant the higher concentration of radionuclides and colloids are in solution. In this context it can alter the view on the consequence of the RNT by groundwater.

The problem under consideration has a rather trivial analytical solution in the case where colloid concentration considerably exceeds radionuclide concentration $\left(C_{1}>>C_{2}\right)$. 

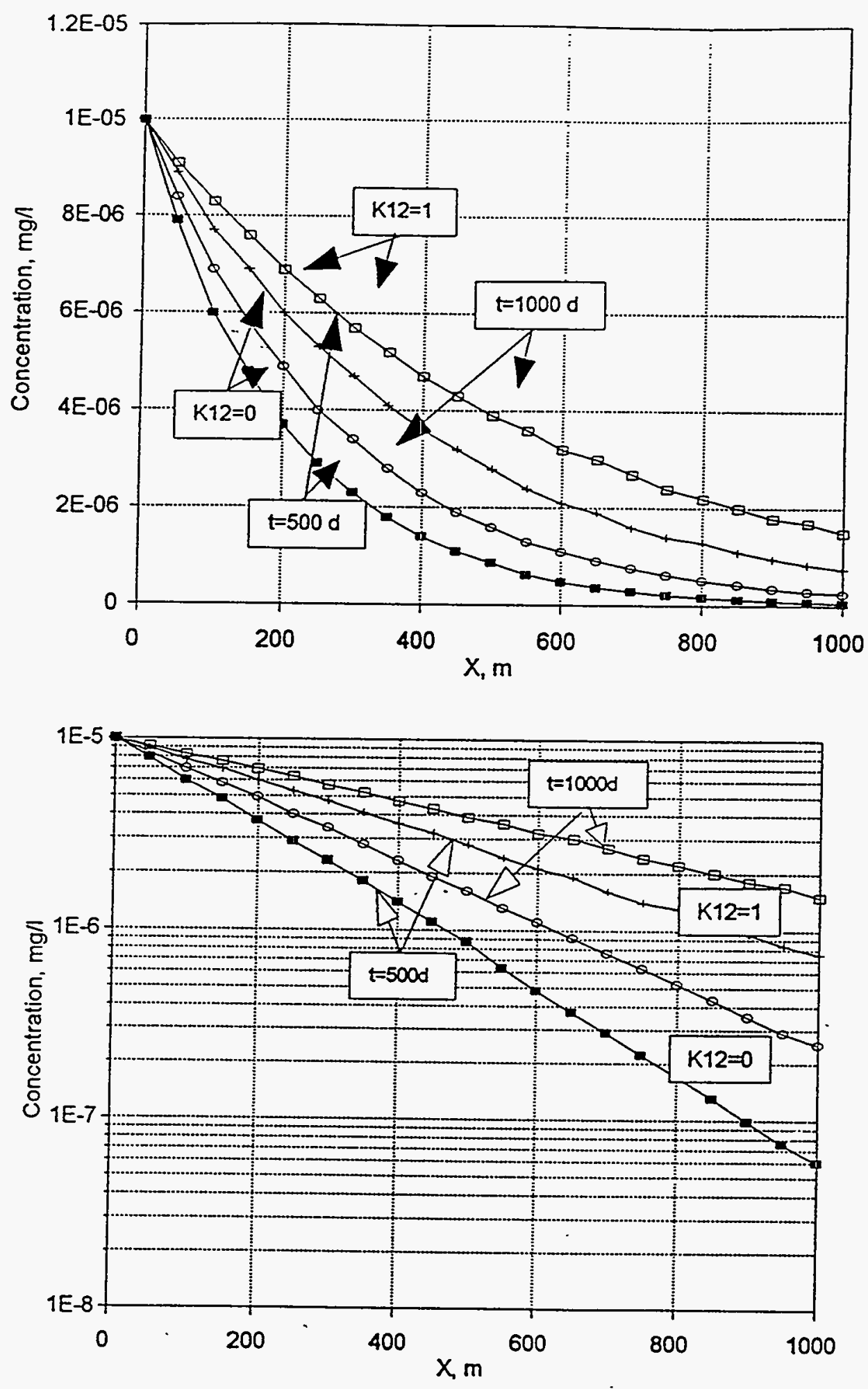

Fig.1. Influence of the colloidal fraction on radionuclide transport $v=0.05 m^{-1}, n=0.001, K_{a} S_{b}=0.005, \lambda_{m}=0.0001 d^{-1}$, $C_{0 m}=0.00001 \mathrm{mg} \mathrm{L}^{-1}, C_{000 \mathrm{~d}}=1.0 \mathrm{mg} \mathrm{L}^{-1}$, $\Delta x=5 \mathrm{~m}, \quad \Delta t=1 d, \quad l=1000 \mathrm{~m}$ 
When it occurs the set of equations (8) is transformed into a linear equation which has been solved by Tang et al., 1981. In this solution, however, one should use some effective parameters instead of the relative volume of fractures $(n)$ and complex mass-exchange parameter $\left(\lambda_{m}\right)$. So, for the model based on the assumption of Elemental Representative Volume (Appendix 2 ) the correction procedure can be represented as follows:

$$
\begin{aligned}
& n \rightarrow n_{e}=n+\frac{K_{a} S_{b}}{1+F K_{d} C_{20}}, \\
& \lambda_{m} \rightarrow \lambda_{m e}=\frac{\lambda_{m}}{\left(1+F K_{d} C_{20}\right)^{2}} .
\end{aligned}
$$

It can be seen that the presence of colloids in solution makes radionuclides move faster because both the values of effective sorption and complex mass-exchange parameters have been decreased.

Finally, some useful assessment showing the influence of colloid formation on masstransport in fissured-porous rocks can be obtained by using the method of "integral balance". Hence, if one supposes that the motion of an advanced front of a displacing solution is determined by the characteristic $t=t(x)$ which controls the intensity of ion saturation of porous blocks (Castaing, 199I)

$$
w_{s} \approx \frac{\sqrt{\lambda_{m}}}{\sqrt{\pi\left(t-t_{f}\right)}} C_{20} ; t>t_{f}
$$

then the integration of the equation (A2) without decay, will yield:

$$
t_{f}=\frac{n+K_{a} S_{b} /(1+a)}{v} \cdot x+\left[\frac{\sqrt{\pi \lambda_{m}}}{2 v(1+a)}\right]^{2} x^{2},
$$

where $a=F K_{d} C_{20}$. As in the previous evaluations, one can see that high values of the constant " $a$ " ( $a>>1$ ) will decrease not only the sorption potential of the fracture surfaces, but also reduce the damping role of the porous matrix. For the limiting case $t_{f}=n x / v$, which corresponds to the transport of nonreactive components in homogeneous media. 


\section{Analysis of the RNT in multicomponent systems}

The models have been just analyzed and examples of their practical use are based on the Kd-concept. Meanwhile the concept has been acutely criticized for the last decade. The reason isb that in real geochemical systems the distribution coefficient is changed over time and space because of the non-steady-state concentration field within the area influenced by industrial impact on groundwater.

This Section is concerned with the assessment of the level of expected errors that appear because of applying the simplified $\mathrm{Kd}$-approach. Similar attempts have been made in numerous previous studies. Nevertheless we wanted to check some calculation situations which are close to the problem of the risk assessment strategy developed for the NPP' projects.

To imitate the migration process a special computer model of multicomponent transport has been worked out (MST1). It includes a hydrogeochemical module for equilibrium thermodynamic computations in "groundwater/minerals" systems based on the MNEQL code (the version SURFEQL by Bales, 1987). The code has an option for simulating sorption processes by treating them as surface complexation reactions (Appendix 4). Among the traditional geochemical interactions taken into account are: (a) complexation species in liquid phase, (b) dissolution/precipitation of the mineral phase; (c) acid/alkaline and oxide/redox reactions. Accepted technique for mathematical formalization of chemical interactions and easyly updatable thermodynamic data-base allow to study a wide range of problems.

The transport module of MST1 provides numerical solution of the set of $1 \mathrm{D}$ differential equations of advective dispersion (Yeh and Tripathi, 1991; Carnahan, 1992):

$$
\begin{aligned}
& n \frac{\partial C_{i}^{T}}{\partial t}+\lambda_{i} n C_{t}^{T}+w_{i}^{T}=L\left(C_{i}^{T}\right), i=1, \ldots, N_{c} \\
& w_{i}^{T}=\frac{\partial}{\partial t}\left[S_{i}+\sum_{k=1}^{N_{p}} a_{i k} P_{k}\right]+\lambda_{i}\left[S_{i}+\sum_{k=1}^{N_{p}} a_{i k} P_{k}\right] \\
& C_{i}^{T}=C_{i}+\sum_{j=1}^{N_{z}} a_{i j}^{x} X_{j} \\
& L(\cdot)=n D \nabla^{2}(\cdot)-v \nabla(\cdot)
\end{aligned}
$$


where $C_{,}\left(j=1, \ldots, N_{c}\right)$ is the concentration of the basic species $C_{j}$ containing component $\mathrm{j}$; $X_{1}\left(i=1, \ldots, N_{x}\right)$ is the fluid-phase concentration of complex $X_{i} ; S_{j}$ is the sorbedphase concentration; $P_{k}$ is the concentration of a precipitate $P_{k} ; a_{i j}$ is the number of moles $C_{j}$ per mole $X_{i} ; a_{i k}$ is the number of moles of basic species per mole of solid $P_{k} ; w_{i}$ is the sink-term, $\lambda_{i}$ is the decay constant.

Solution of the equations (13) is carried out with the finite-difference method including an implicit scheme and a Gauss-Seidel iteration procedure with upper relaxation.

Coupling hydrogeochemical and transport modules is based on a so-called "two-step" technique. According to it two modules work consequently: during the first step the equations of advective dispersion are solved with the assumption that all species are conservative; the obtained concentration distributions are used for the thermodynamic calculations including sorption equilibriums that result in computing the mobile forms of the basic components and the sink-function $w_{i}$. In addition to the simulation procedure for the surface complexation reactions, it is allowed to use a special code option for physical adsorption governed by the linear Henry's law. For the latter it is supposed that only components migrating in the simplest ionic forms are allowed to be adsorbed thus the number of the coefficients $K_{d_{1}}$ is equal to the number of the basic components.

The MST1 code has been supplemented with an option for simulating the massexchange processes in fractured- porous reservoirs. Effective approaches described above (Section 3) are used for this purpose.

At the present time the first stage of testing program procedure has been implemented. Thus, by switching off the geochemical module we managed to get numerical results wich were in good agreement with the well-known analytical solutions for the "singlecomponent" transport case. In order to quantify the reliability of the procedure coupling geochemical and transport modules three- component transport process have been simulated.It was supposed that a reactive component $M_{1}$ participates in reactions of complexation involving ligands $L_{2}$ and $L_{3}$ : 


$$
\begin{array}{ll}
M_{1}+\bar{X} \rightarrow \overline{M_{1} X}, \quad K=\rho K_{d}=1 . \\
M_{1}+L_{2} \rightarrow M_{1} L_{2}, \quad K=0.5 \\
M_{1}+L_{3} \rightarrow M_{1} L_{3}, \quad K=1.0
\end{array}
$$

The model results were compared with the output data obtained with the SATRA-CHEM code by Lewis et al., 1986 based on a "one-step" technique of coupling the geochemical and transport parts of the numerical problem (Fig.2). As one can see both models lead to results which agree fairly closely: maximum differences are monitored within peak values of ligand concentrations and do not exceed $5 \%-7 \%$. The nonmonotonic character of $L_{2}$ and $L_{3}$ curves is explained by the decay of $M_{1} L_{2}$ and $M_{1} L_{3}$ complexes near the moving boundary interface of two solutes that results from disturbing equilibrium because of metall-ion $M_{1}$ adsorption.

Further the MST1 code was used to study some aspects of the RNT under conditions of releasing radionuclides during failure of nuclear reactors (the first pathway of the radioactive release process). These conditions are outlet characterized by the presence of radionuclides in groundwater at extremely high concentrations. The major aim of this analysis is to assess the feasibility of applying the simplified $K_{d}$ models for the migration process.

Two variants of the model assessments serve as a basis for the analysis (Table 2). In the first variant (I) the differences in the concentrations of the main components in the background water and in the contaminant source were assigned to be very significant; it was done to enhance the intensity of interactions between components in the liquid and solid phase. In the second variant (II) the differences were smoothed out to diminish the interactions.

Transport parameters of the model were assigned to be:

- Darcy velocity, $v=0.1 \mathrm{md}^{-1}$

- Porosity, $n=0.1$

- Dispersivity, $\delta=1.0 \mathrm{~m}$

Length of the model, $\mathrm{L}=320 \mathrm{~m}$. Grid parameters of the model: $\Delta x=4 m, \Delta t=5 d$.

The governing geochemical reactions are as follows: 


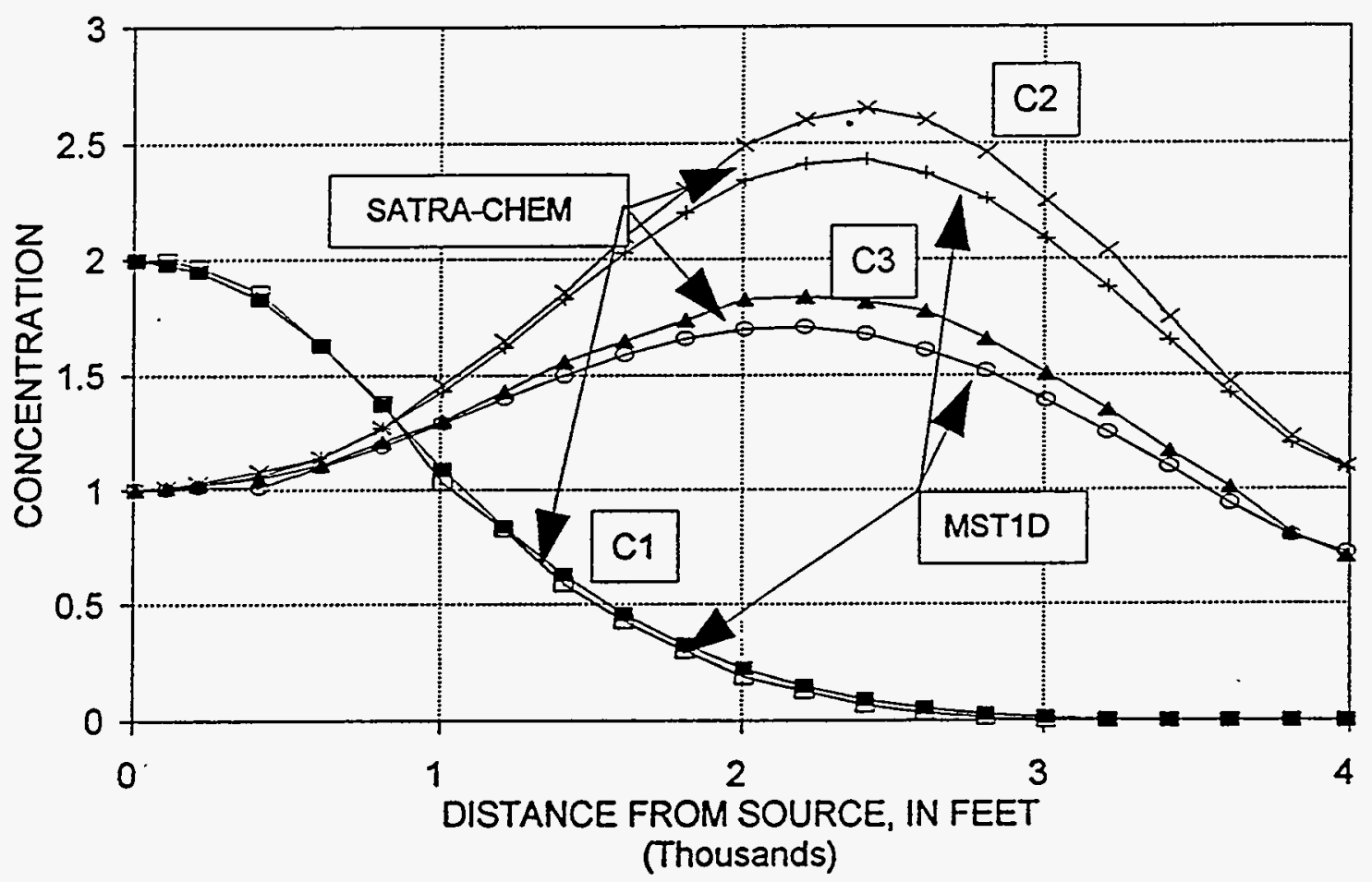

Fig.2. Test example: Transport with equilibrium sorption (simulation with SATRA-CHEM and MST1) 
Table 2. Hydrogeochemical characteristic of initial and boundary conditions for the basis (I and II) modeling variants

\begin{tabular}{|c|c|c|c|c|c|c|c|c|}
\hline \multirow{2}{*}{$\begin{array}{l}\text { Number } \\
\text { of } \\
\text { va-iant }\end{array}$} & \multirow{2}{*}{$\begin{array}{l}\text { Initial } \\
\text { and } \\
\text { boundary } \\
\text { conditions }\end{array}$} & \multicolumn{7}{|c|}{$\begin{array}{l}\text { Total concentration of the } \\
\text { basic components, mol } \star 1^{-1}\end{array}$} \\
\hline & & $\mathrm{Sr}$ & $\mathrm{Na}$ & $\mathrm{Ca}$ & $\mathrm{Cl}$ & $L$ & $\mathrm{pH}$ & $>\mathrm{SOH}$ \\
\hline 1,11 & $\begin{array}{l}t-0 \\
x>0\end{array}$ & 4.9E $(-10)$ & $0.8 E(-4)$ & 9.7E(-4) & 3. $0 E(-3)$ & 1. $O E(-4)$ & 5.0 & $5.0 E(-3)$ \\
\hline 1 & $x-0$ & $1.0 E(-3)$ & 1. OE $(-1)$ & 1.OE $(-2)$ & 1. OE $(-1)$ & 1. OE $(-4)$ & 5.0 & $5.0 E(-3)$ \\
\hline II & $x-0$ & 1. OE $(-6)$ & 2. OE $(-3)$ & 2. OE $(-3)$ & 6. OE $(-3)$ & 1. OE $(-4)$ & 5.0 & $5.0 E(-3)$ \\
\hline
\end{tabular}




$$
\begin{array}{ll}
\left.>\mathrm{SOH}=H^{+}+\right\rangle \mathrm{SO}^{-} & \lg \mathrm{K}=-10.3 \\
\rangle \mathrm{SOH}+\mathrm{H}^{+}=\right\rangle \mathrm{SOH}_{2}^{+} & \lg \mathrm{K}=5.4 \\
\left.\left.\mathrm{Sr}^{2+}+\right\rangle \mathrm{SOH}=\right\rangle \mathrm{SOSr}^{+}+H^{+} & \lg \mathrm{K}=1.0 \\
\left.\left.\mathrm{Na}^{+}+\right\rangle \mathrm{SOH}=\right\rangle \mathrm{SONa}+H^{+} & \lg \mathrm{K}=-1.0 \\
\left.\left.\mathrm{Ca}^{2+}+\right\rangle \mathrm{SOH}=\right\rangle \mathrm{SOCa}+H^{+} & \lg \mathrm{K}=1.0 \\
\mathrm{Sr}^{2+}+L^{2-}=\mathrm{Sr} L & \lg \mathrm{L}=4.0
\end{array}
$$

The parameters used to model the surface complexation (Appendix 4) are as follows:

- Layer capacitance, $C=1.0 \mathrm{Fm}^{-2}$;

- Solid surface area, $S_{A}=1.0 \mathrm{~m}^{2} \mathrm{~g}^{-1}$;

- Solid-to-water mass ratio, $C_{s}=1000 \mathrm{~g} \mathrm{~L}^{-1}$;

- Specific surface area, $S_{A S}=S_{A} \cdot C_{S} / n=1.0 \cdot 10^{7} \mathrm{~m}^{-1}$.

Besides several chlorid - and hydro-complexes were taken into consideration however they did not play any principal role in the process.

The obtained concentration curves $C(x, t)$ are shown in the plots (Fig.3 and 4). On the other plot (Fig.5) one can see the changes of the effective values of the distribution coefficient $K_{d}^{S r}$ calculated through current ratio $S_{S r} / C_{S r}$, where $C_{S r}$ and $S_{S r}$ are the total concentrations of strontium in the liquid and solid phases (in composition of the surface complexes) phases.

It is of interest that intensive exchange processes taking place at the model variant I resulted in extreme behavior of the $K_{d}^{S r}(x)$ function. This can be explained by calcium accumulation

in the solution by being replaced from surface complexes by sodium. This decreases the strontium sorption because of the competition phenomenon. Therefore the sorption ability of strontium deminishes within the dispersion zone where the peak of calcium concentration occurs is locally reduced.

At the same time the variant II illustrates the relaitive stable behaviour of the $K_{d}^{S r}$ parameter that results from low values of concentration gradients.

For the next step of model investigations averaged values of $K_{d}^{S r}$ parameter were used in 


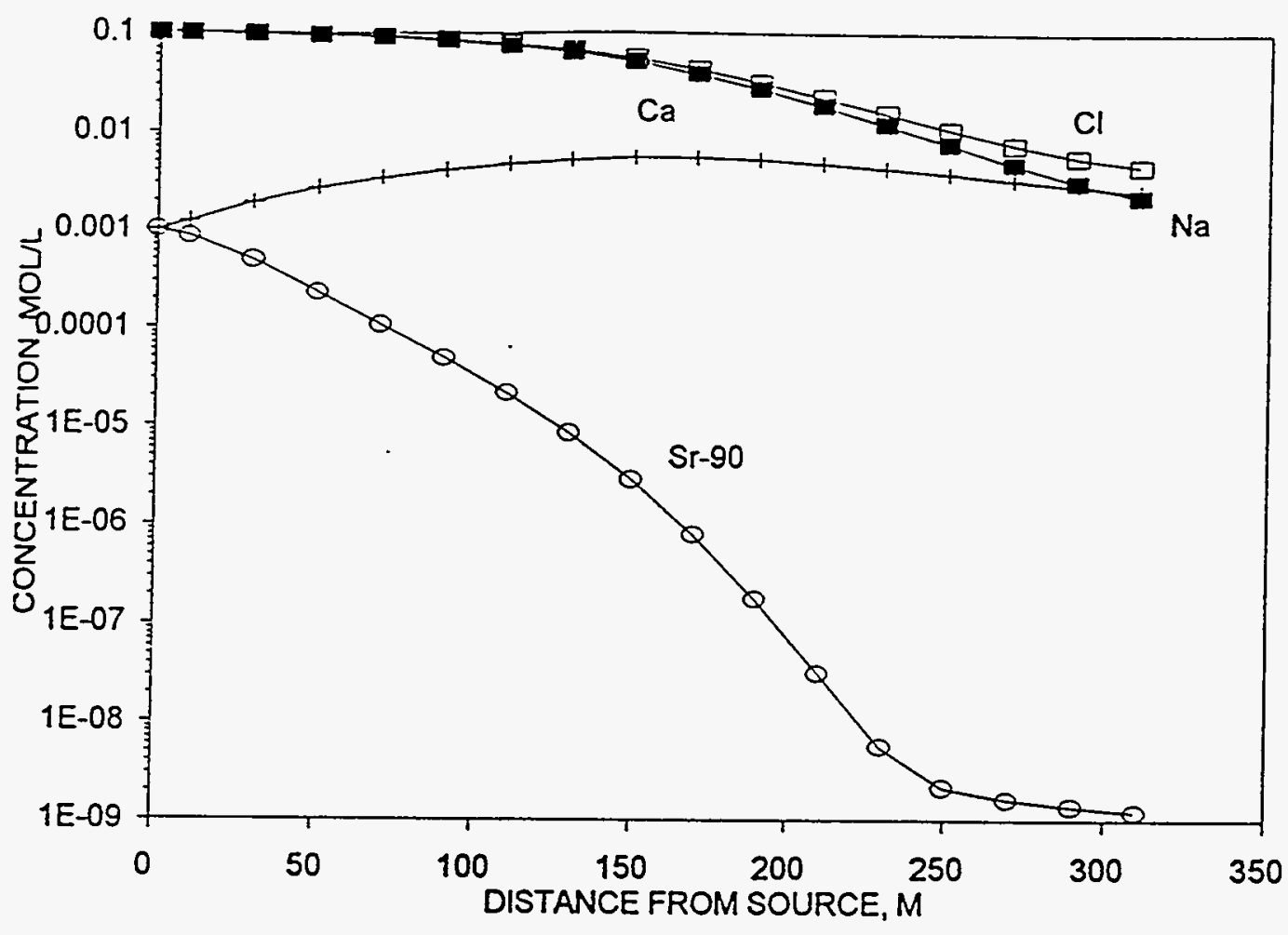

Fig.3. Concentration curves $C_{i}(x)$ for the model variant I

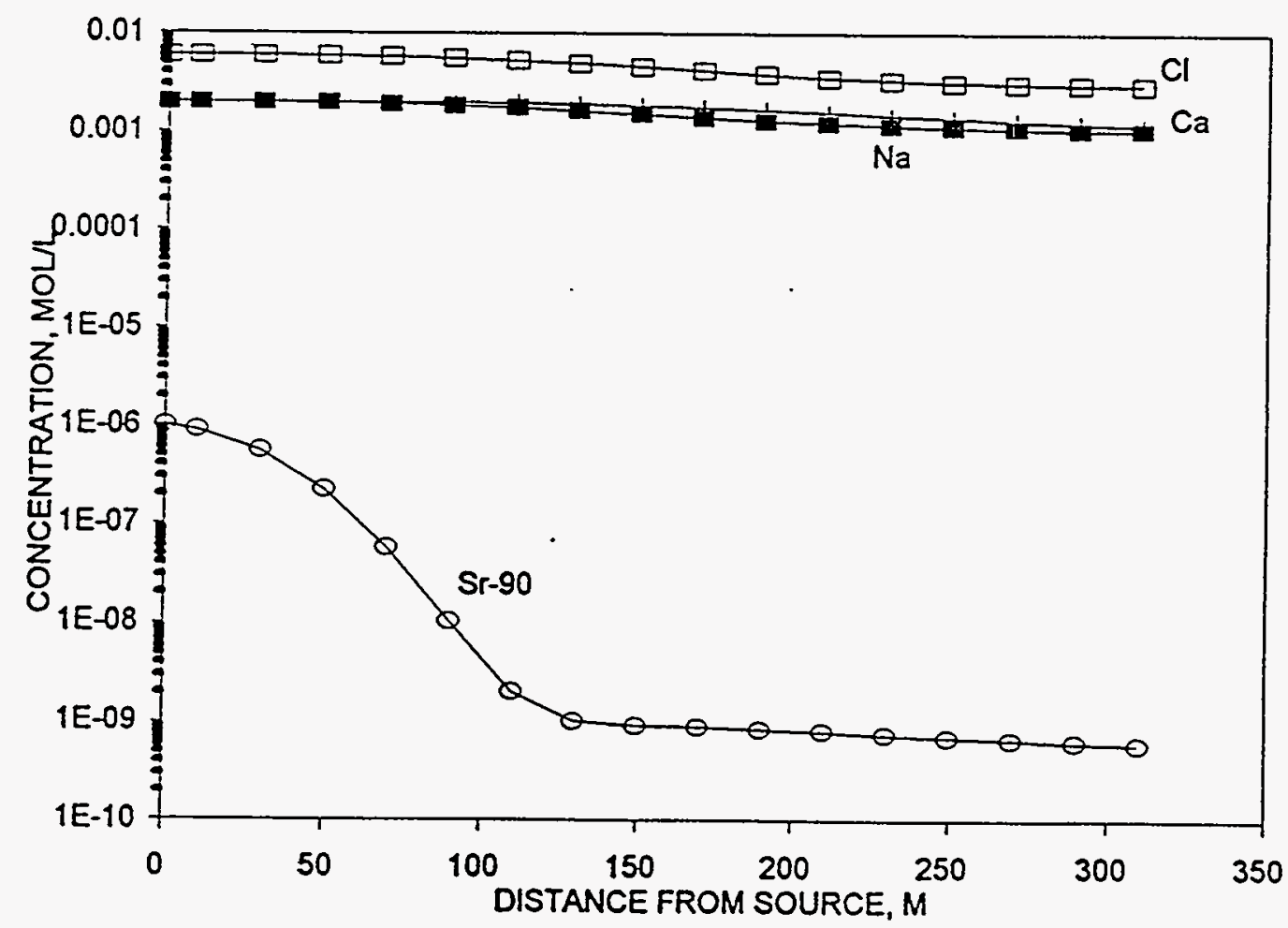

Fig.4. Concentration curves $C_{i}(x)$ for the model variant $\Pi$ 


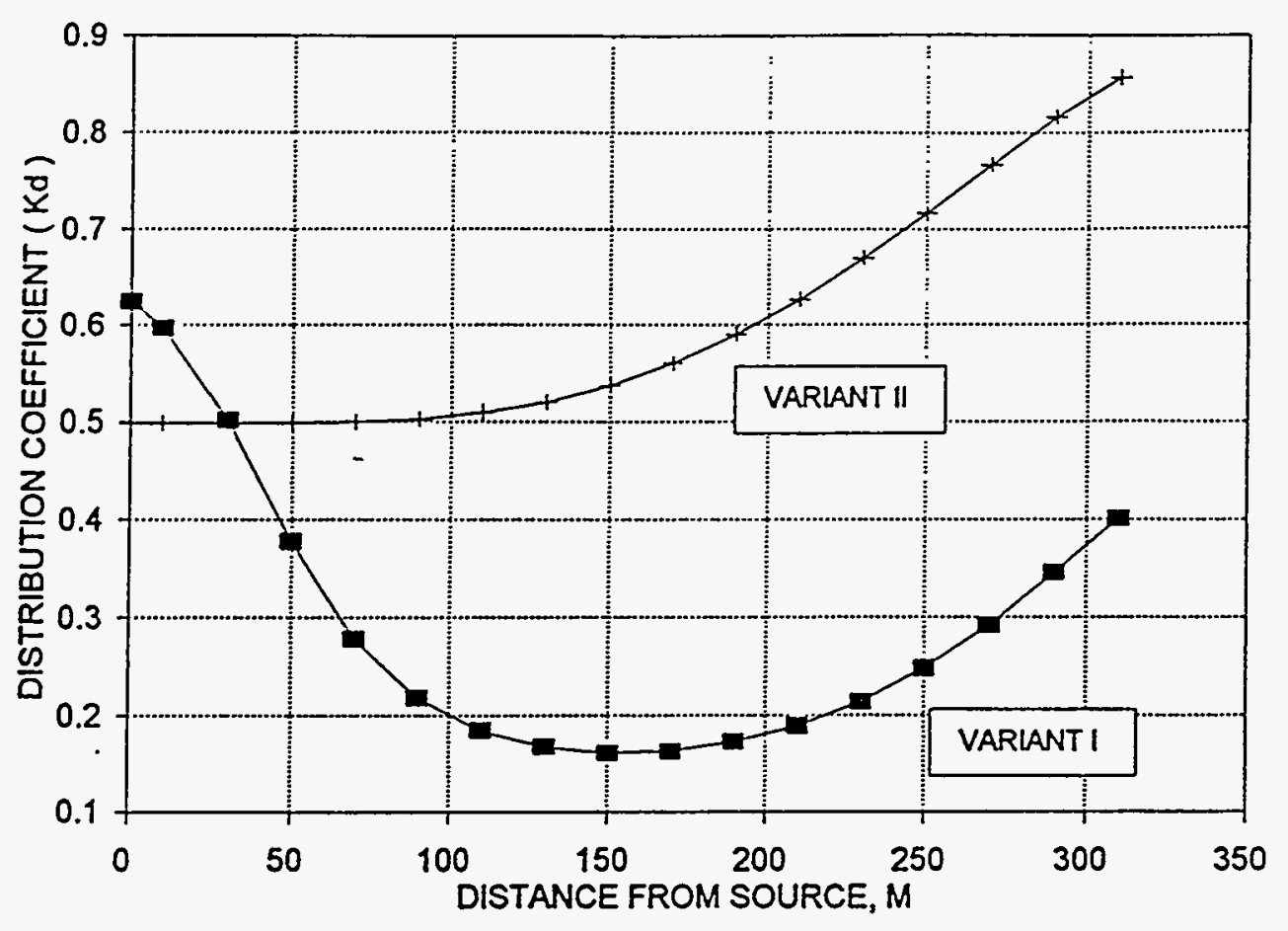

Fig.5. Plot of the distribution coefficient versus distance $(t=150$ days): $I$ and $I$ are model variant (see Table2)

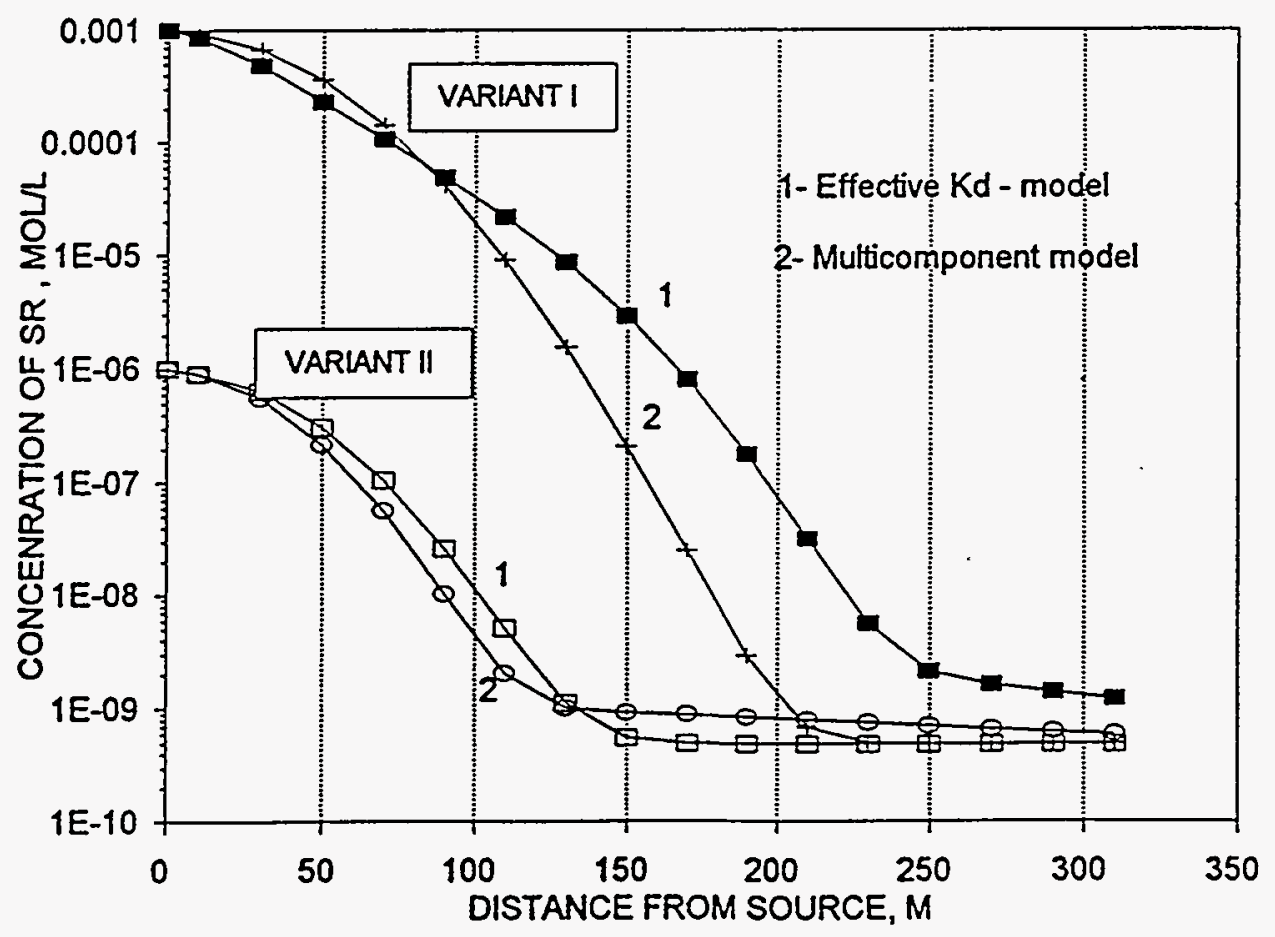

Fig.6. Comparing numerical solutions obtained in the context of: (1) the Effective Kd-model, (2) The Multisolute model 
the finite-difference model of "one-component" transport. $C_{S r}$ - distributions obtained were compared with the results of the multicomponent transport simulation (Fig.6). Thus it enables us to evaluate the efficiency of two approaches. The main conclutions of this analysis are as follows:

1. If the relation between component concentrations and thermodynamic parameters of the hydrogeochemical system is such that radionuclides migrate under unsteady-state conditions caused by changes of other concentration functions one can expect unstable behaviour of the sorption distribution coefficient. As a result it is impossible to choose an appropriate (averaged) value of the $K_{d}$ constant which would be good enough to describe the RNT process: errors in the area of low radionuclide concentrations can reach several orders of magnitude.

2. If the radionuclide concentration in the contaminant source is much less than the concentrations of the main components and major changes of the latter take place in front of the waste/groundwater interface one can try to pick out the $K_{d}$-constant satisfactorily describing radionuclide migration.

3. For a given type of industrial impact on the underground hydrosphere the $\mathrm{Kd}$ approach is supposed to be reliable for forecastings of the subvertical RNT that is conditioned by

the areal recharge of water polluted by precipitated radionuclides (the second pathway of radioactive release). In this case the transport process is not associated with strong changes of chemical composition of groundwater.

For the first scenario the forecasts would require using the multisolute transport models.

\section{A simplified model for analysis of the infiltration type of groundwater pollution}

Participating recharge in forming a groundwater flux requires the intimate linkage between the flow and mass-transport parts of the problem. Model construction needs to take into account the nonuniform character of the radionuclide input to the water table, which 
is conditioned by variations of the physical properties of the unsuturated zone (Shestopalov and Gudzenko, 1993). This has to be reflected in the calculation scheme as well.

The model is based on a fundamental solution for a fixed flow path (Fig.7). If a short length $x_{1}<x<x_{2}$ of the flow path is polluted with intensity $P_{\varepsilon}$ (Fig.8) the solution for the output concentration function is expressed as

$$
\begin{aligned}
& C=P_{\varepsilon}^{*} \exp \left[\left(-\lambda+\varepsilon^{*}\right) t\right] \text { when } t_{2}^{0}<t<t_{1}^{0} \text { or } \\
& C=0 \text { when } t<t_{2}^{0} \text { and } t>t_{1}^{0}, \\
& \text { where } t_{i}^{0}=m n \int_{x_{1}}^{L}\left(B_{x} / Q_{x}\right) d x
\end{aligned}
$$

is the residence-time for particles coming into the aquifer at poins $x_{1}$ and $x_{2} \quad\left(L>x_{1}\right.$ and $\left.x_{2}\right) ; B_{x}$ is the current width of the flow path determining the flow rate $Q_{x} ; \varepsilon^{*}=\varepsilon /(m n)$ ( $\varepsilon$ is recharge rate, $\mathrm{m}$ is the thickness of the aquifer, $\mathrm{n}$ is the porosity); $P_{\varepsilon}^{*}=P_{c} /(m n), P_{\varepsilon}$ is the density of groundwater surface pollution,

$$
P_{\varepsilon}=P_{f} \exp \left(-\lambda t_{A}\right),
$$

$P_{f}$ is the density of the land surface pollution, $t_{A}$ is the residence time for the radionuclide transport through the unsaturated zone.

For determining the time-characteristic $t_{A}^{0}$ one can use numerical as well as analytical techniques. It is important that solution (14) can be generalized for a case of variable recharge rate $\varepsilon=\varepsilon(x)$ (in X-direction), which can be associated with the non-ununiformity of hydraulic conductivity in the unsaturated zone. For step-functions of $E(x)$ and $Q_{x}(x)$ superposition of solution (14) leads to the equation:

$$
C=P_{\varepsilon}^{*} \exp (-\lambda t) \exp \left(-\sum_{j=j^{*}}^{N_{j}} \Delta t_{j}^{0}\right)
$$

which is valid in the interval $t_{1}^{0}<t<t_{2}^{0}$, where $t_{j}^{0}=\sum t_{j}^{0}$ (ranges from $\mathrm{j}=1$ to $\mathrm{Nj}, \mathrm{j}$ is the current number of the block, $\mathrm{Nj}$ is the finite block belonging to the cross-section $\mathrm{x}=\mathrm{L}$ ).

Finally, using the superposition principle for the case of variable intensity of land surface pollution yields 


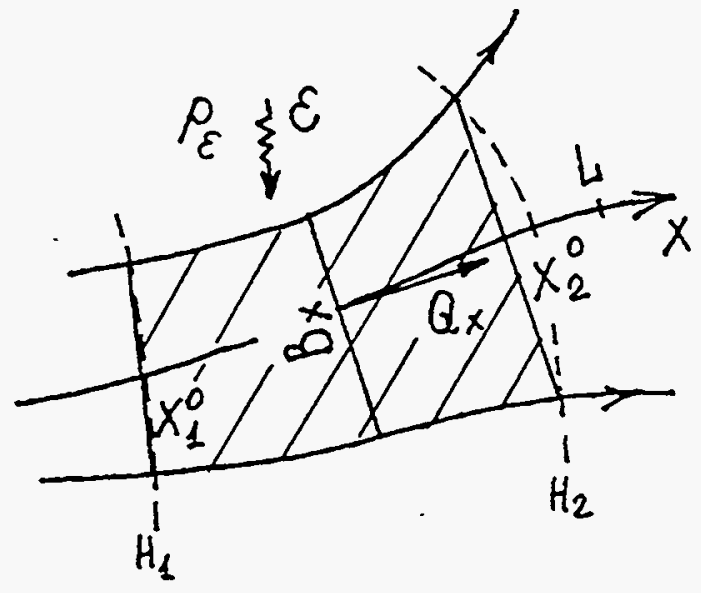

Fig.7. Schematic representation of the flow-path with elements of flow discretisation.

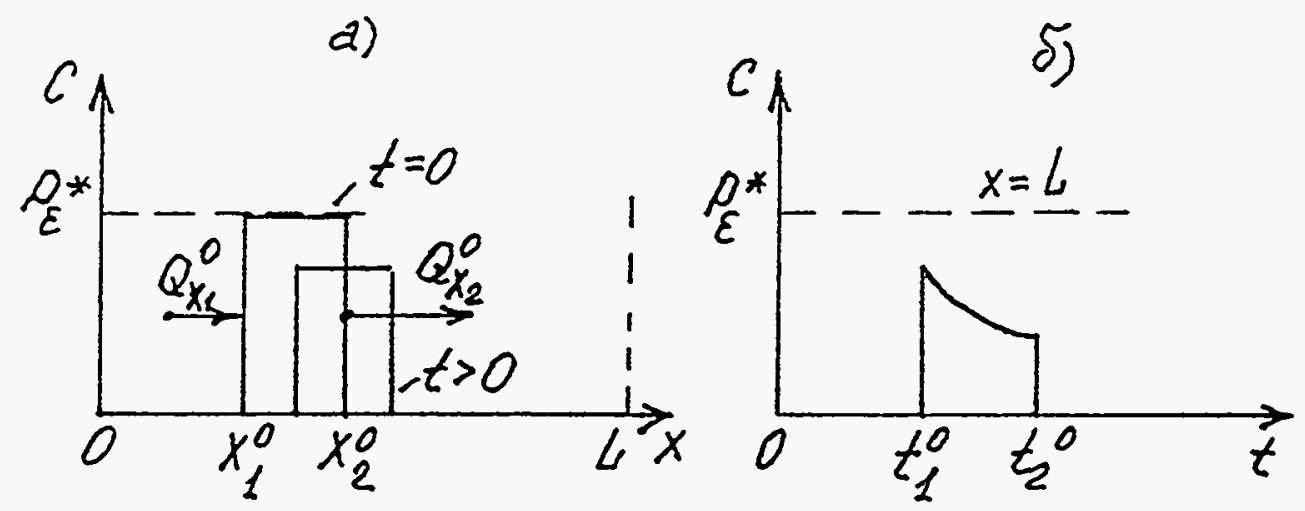

Fig.8. Scheme of zonal distribution of component on groundwater table (a) and schematic plot for output function (b) 


$$
C=\sum_{k=1}^{K} P_{\varepsilon k}^{*} \exp (-\lambda t) \exp \left(-\sum_{j=j_{k}} \varepsilon_{j}^{*} \Delta t_{j}^{0}\right),
$$

where $\mathrm{K}$ is the number of the $j_{k}^{*}$ zone providing radionuclides input at crossection $\mathrm{x}=\mathrm{L}$ at time $t=t_{j_{t}}^{0}$.

The analytical-and-numerical approach considered above have been applied to analyze relevant environmental problems for the NPP design. Output concentration functions resulted from the analysis of concrete situations (Rumynin et all.,1993) turned out to be rather complicated that is associated with nonuniformal character of land surface pollution as well as a variety of hydraulic conductivity of surface deposits.

\section{Conclusions}

The major conclusions of our analysis are as follows:

(1) The substantial discrepancies between the formal IAEA requirements for the hydrogeo-environmental assessments of NPP projects and the present design practice derive from uncertainties concerning including the parameters of radioactive release (for different scenarios of hazardous accidents at NPP) into the set of hydrogeological models. Having analyzed the output characteristics of the risk-assessment models (for some type of industrial nuclear reactors) we managed to conceptualize the hydro-geo-environmental problem under consideration.

(2) The forecasts of the RNT in groundwater are based, principally, on proper mathematical models of the advective- dispersive type. Such statement of the problem with due regard to dispersive components of mass-transport is of particular importance for the first pathway of an emergency radioactivity release which facilitates the formation of local (point) sources of contamination. In this case a transversal spreading of a substance appears to be a significant factor retarding the overall scale of contamination.

At the same time, forecastings of regional groundwater contamination by radionuclides recipitated on the land surface (the second pathway) may be reduced to the consideration of 
the most simple convective balance schemes for water-bearing strata coupled with onedimensional solutions for transport within the unsaturated zone.

(3) Description of the advanced fronts of contamination plumes characterised by rather low values of relative concentrations $\left(C<1 \cdot 10^{-10}-1 \cdot 10^{-12}\right)$ is of prime interest for the hydro- geological forecasts under consideration because the radio- nuclide content at the contamination sources are $\left(\cdot 10^{8}-1 \cdot 10^{10}\right)$ times more than the maximum admissible levels. To improve the accuracy of the RNT forecastings special mathematical techniques have to be applied. They can be based on coupling numerical and analytical approaches.

(4) For example, being supplemented by analytical modules the traditional numerical codes allow to take into account the internal heterogeneity in fractured-porous reservoirs attributed to the diffusive exchange between fracture water and pore water: very often the kinetics of this exchange result in a more substantial influence on the dispersion process than the spatial nonuniformity of the permeable medium or variations of fracture properties and morphology. In fractured-porous strata radionuclide decay proceeds not only in the fractures but also in the porous matrix. This could substantially shift the permissible range of application for different calculation schemes used for describing mass- exchange between mobile and immobile water. Preliminary estimations show that the scheme of "unlimited matrix capacity" could be preferable to the scheme of "quasi-steadystate regime" for long-term forecasting, especially in the case of intensive sorption inside the porous matrix.

(5) To modify the governing equations (for nonreactive solute transport) one has to include a source function transformed by taking into account the radioactive decay. So far we have obtained some analytical solutions for the mentioned basic schemes which can be extended to cases of linear sorption of radionuclides in mobile and immobile zones.

In order to couple ionic and colloidal migration forms within the combined RNT model the regularities of their interactions in liquid phase have to be analyzed. Following previous investigations we assumed the analogous to the simplest equilibrium complexation reactions. Such an approach leads to a nonlinear set of equations which can easily be transformed into a form convenient for numerical simulation by the finite differences method. We have implemented a computer realization of appropriate algorithms in a one-dimensional version. 
In case of excessive colloidal concentration in the solution the results are rather trivial: the set of equations is transformed into a linear equation for which some useful analytical solutions and criterions can be found.

(6) Under certain conditions many of the existing one-component $\mathrm{Kd}$ models are not always suitable for long-term forecasts because of the high sensitivity of the empirical

parameter $K_{d}\left(\right.$ or $\left.K_{a}\right)$ to possible variations of hydrogeochemical conditions along the flow path. On the other hand the multicomponent trans- port models require an enormous number of thermodynamic constants which can not be provided in real practice. It makes one look for a compromise between these two approaches which is supposed to be found by further development of conceptualization principles for the migration process under consideration.

\section{ACKNOWLEDGMENTS}

This work was prepared under the auspices of Russian-American Center for Contaminant Transport Studies at the Lawrence Berkeley Laboratory. We appreciate the funding from the Department of Energy's Office of Environmental Management, Office of Technology Development (DOE/EM-OTD) and the Office of Energy Research, Office of Basic Energy Sciences (DOE/ER-BES) through Contract Number DC-AC03-76SF0098. 


\section{References}

Bales, R.C. (1987) Introduction to MINEQL and SURFQL. University of Arizona, $41 \mathrm{p}$. Bear, J. (1972) Dynamics of fluid in porous media. Amer. Els. N.Y.,764p.

Carnahan, C.L. (1992) Mathematical basis for THCC code. Lawrence Berkeley Laboratory, University of California, 200p.

Castaing, $R$. (1991) Un modele simple pour la migration dans un ilien fracture. J. Hydrol. 125(1-2), 55-92.

Doughely, D.E. \& Bagtzoglou, A.C. (1993) A caution on the regulatory use of numerical solute transport models. Groundwater, 31(6), 1007-1010.

Hydrogeological Aspects of Construction Sites for Nuclear Power Stations. (1986), Vienna, Safety Manual. Series of Publications on Safety of International Atomic Energy Agency 50, S6-S7, $71 \mathrm{p}$.

Intentional Project to Study Validation of Geosphere Transport Models. (1989) Gotab.Stockholm, Intraval-Progress Report 4, $80 \mathrm{p}$.

Janhke, F. M. \& Radke, C. J. (1987) Electrolyte diffusion in compacted montmorylonite engineered barriers. Coupled Processes associated with Nuclear Waste Repositories. Edited by Chin-Fu Tsang. Academic Press. Inc., 287-297.

Kamineni, D. C. Vandergraaf, T. T. \& Ticknor, K. V. (1983) Characteristics of radionuclide sorption on fracture - fillings minerals in the Bye-Dashwa Lakes Pluton, Atikokan, Ontario. Canadian Mineralogist 21, 625-636.

King, K. L. \& Killoy, R. W. D. (1990) Chemical controls on subsurface radionuclide transport: A review of studios at Chalk River Laboratories.-Transport and Mass exchange processes in sand and gravel aquifers: Field and Modelling Studious. Proceedings of the Int. Conf. and Workshop held in Ottawa, Canada, October 1-4, 737-756.

Konikow, L. F. \& Bredehoef, I. D. (1983) Computer model of two-dimensional solute transport and dispersion in ground water. Techniques of water-Resources Investigation of the United State Geological Survey, Chapter C2, Book 7, 90 p. 
Koss, V. \& Kim, J.I. (1990) Modeling of strontium and speciation in a natural sedimentgroundwater system. Journal of Contaminant Hydrology, 6, 267-280.

Lewis, M. F. Voss C. I. \& Rubin, J. (1986) Numerical simulation of advective-dispersive multisolute transport with sorption, ion exchange and equilibrium chemistry. Water Resources Investigations Report 86-4022, Reston, Verginia, 165 p.

Lieser, K.H. \& Steinkopff, T. (1989) Sorption equilibria of radionuclides or trace elements in multicomponent system. Radiochim. Acta, 47, 55-61.

Mironenko, V. A. \& Rumynin, V. G. (1986) Migration Tests and Observations in Aquifers. Moscow, Nedra, $240 \mathrm{p}$.

Rasmuson, A. \& Neretnieks, $J$. (1986) Radionuclide migration in strongly fissured zones: The sensitivity to some assumptions and parameters. Wat. Resour. Res. 22(4), 559-569.

Ronen, D. Magaritz, M. Weber, U. \& Amiel, A. J. (1992) Characterization of suspended particles collected in groundwater under natural gradient flow conditions. Wat. Resour. Res. 28(5), 1279-1291

Rumynin, V.G. (1983) On theoretical models for subsurface migration in heterogeneous groundwater reservoirs. In : Modelling approaches in Hydrogeology and Engineering Geology. Novocherkassk, 34-46.

Rumynin, V. G. Konosavsky, P. K. \& Pereverseva, S. A. (1992) Hydrogeological Analysis of Consequences of Hazard Accidents at Designed Nuclear Reactors: 1 - Substantiation of predicted models. Geologia i Razvedka, 6, 92-102.

Rumynin, V. G. Konosavsky, P. K. \& Pereverseva, S. A. (1993) Hydrogeological Analysis of Consequences of Hazard Accident at Designed Nuclear Reactors: 2 - Hydrogeological Forecasts of Impacts of Hazard Hypothetical Accident at the Particular Sites. Geologia i Razvedka, 1, 127-137.

Shestopalov, V.M. \& Gudzenko, V.V. (1993) Effects of the Chernobyl Desaster on natural waters. Proc. of The Second USA/CIS Joint Conf. Washington, USA, 41-49.

Tang, D. H., Frind, E. O. \& Sudicky, E. A. (1981) Contaminant transport in fractured porous media: Analytical solution for a single fracture. Wat. Resour. Res. 17(3), 555-564. 
Ticknor, K. V. \& Vandergraaf, T. T. (1986) A method for producing autoradiographs of rough surfaces. Nuclear and Chemical Weste Management, 6, 233-239.

Ticknor, K. V., Vandergraaf T. T. \& Kamineni, D. C. (1989) Radionuclide sorption on primary and fracture-filling minerals from the East Bull Lake pluton, Massey, Ontario, Canada. Applied Geochemistry 4, 163-176.

Ticknor, K. V., Kamineni, D. C. \& Vandergraaf, T. T. (1991) Flow path mineralogy: Its effects on radionuclide retardation in the geosphere. Mat. Res. Soc. Symp. Proc. 212, 661-669.

Torok, J., Buckley, L. P. \& Woods, B. L. (1990) The separation of radionuclide migration by solution and particle transport in soil. J. Contam. Hydrol. 6, 185-203.

Van Cappellen, P., Charlet, L., Stimm, W. and Wersin, P. (1993). A surface complexation model of the carbonate mineral aqueous solution interface. Geochimica et Cosmoshimica Acta, $57,3505-3518$.

Vandergraaf, T. T. \& Abry, D. R. M. (1982) Radionuclide sorption on drill core material from the Canadian Shield. Nuclear Technology 57, 399-412.

Vandergraaf, T. T., Ticknor, K. V. \& George, I. M. (1984) Reactions between technetium in solution and iron-containing minerals under oxic and anoxic conditions. American Chemical Society. ACS Symposium Series 246, 26-43.

Vilks, P. \& Dequelare, C. (1991) Sorption behaviour of Sr-85,I-131 and Cs-137 on colloids and suspended particles from the Grimsel Test Site, Switzerland. Applied Geochemistry 6, 553-563.

Vilks, P., Miller, H. G. \& Doern, D. C. (1991) Natural colloids and suspended particles in the Whiteshell Research Area, Manitoba, Canada, and their potential effects on radiocolloid formation. Applied Geochemistry 6, 565-574.

Yeh, G.T. \& Tripathi, V.S. (1991) A model for simulating of reactive multispecies components: Model development and demonstration. Water Res. Res.27 (12), 3075-3094. 


\section{Appendix 1 \\ A short comment on "Kd-approach"}

Traditionally equilibrium sorption is incorporated into a retardation factor $(R)$ through an empirical coefficient of sorption distribution (so called "Kd concept"). There are two major forms of introduction of the retardaction factor: the first one is for granular (porous) sediments (Bear, 1972 and others),the second one is for fractured media (Vandergraaf and Abry, 1982).

Sufficiently detailed examination has been given to radionuclide adsorption in porous sediments. The main parameters controlling such interactions are the total cation exchange capacity $\left(E_{v}\right)$ and the ionic strength of groundwater $(I)$.For example, having generalized experimental data over several sites of the NPP location we obtained a plot (Fig.A.1) which reflects a linear raise of the distribution coefficient $K_{d}$ with increasing $E_{v}$. On the contrary, an increase of I leads to an abrupt drop inradionuclide adsorption. So, by our data, in sufficiently mineralized $(I>0.5)$ water of sand aquifers strontium-90 can behave as an nonreactive component. An abrupt decrease of adsorption for strontium-90 and cesium137 with the increase of bulk dissolved-solids content has been verified by batch experiments performed with montmorillonite clays (Janhke and Radke, 1987).

In the references one can also find data on radionuclide sorption in a matrix of consolidated porous blocks sampled from a fractured rock mass. A noticeable sorption ( $K_{d}$ up to $N \cdot 10 \mathrm{~cm}^{3} \mathrm{~g}^{-1}$ and more) of such radionuclides as strontium-90 and cesium-137, is inherent both to the rocks of sedimentation origin and to highly metamorphosed and even intrusive rocks with matrix porosities of less than 1\% (Rasmuson and Neretnieks, 1986; Intraval - Project Report, 1989).

Adsorption onto the fracture surfaces which is characterised by a parameter $K_{a}$ (dimensional representation $-L$ ) has been studied rather poorly. Nevertheless, a number of the conducted experiments is quite sufficient to prove a noticeable influence of this process, which could be characterised by the dimensionless parameter of adsorption retardation:

$$
R=1+2 K_{a} / b, \quad R=1+K_{a} S_{b} / n,
$$



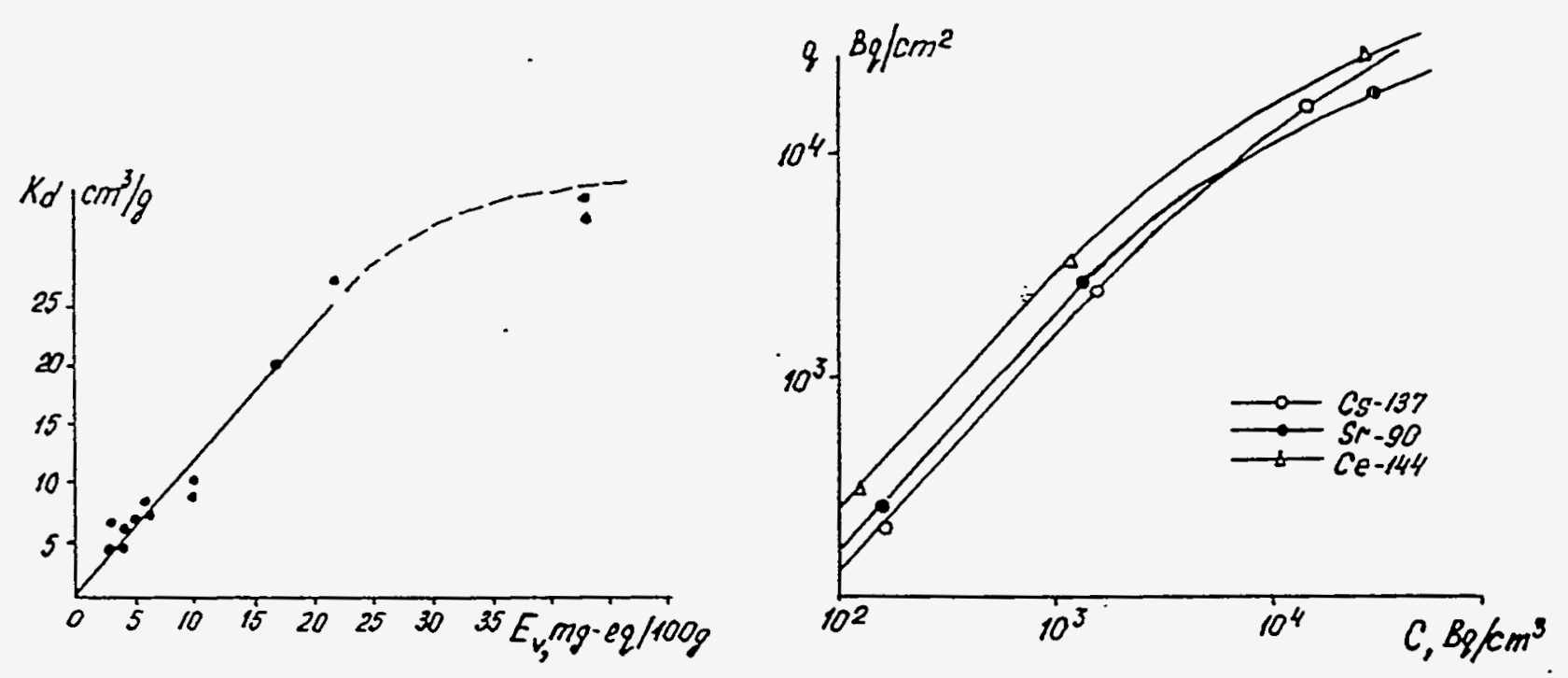

Fig.A.1. $K_{d}$ parameter as a function of the $E_{v}$

Fig.A.2. Isotherms sorption of radionuclides onto the surface of fissures 
- respectively, for a model of a single fracture with apperture" $b$ " and for the statistically averaged model of uniformly fractured rocks (when the assumption of the Representative Elemental Volume is valid) characterised by a specific surface of blocks, $S_{b}$ and a relative fracture volume, $\mathrm{n}$.

For example, in the investigations (Vandergraaf and Abry, 1982) the following ranges of parameter $K_{a}(\mathrm{~cm})$ variations have been established for different radionuclides absorbed at the surface of granite blocks: Sr-90 - 0.09-2.1; Cs-137 - 1.5-53; Cs-134-2.2-24; Pu237 - 1.4-70. We (Rumynin et al., 1992) have obtained the same range of values $K_{a}=0.8$ $1.2 \mathrm{~cm}$ for these isotopes absorbed on granodiorites (Fig.A.2).

The specification of radionuclide adsorption on fracture surface by autoradiografic analysis seems to rather efficient and compatible with the mineralogical study of specimens (Kamineni et al., 1983; Vandergraaf et al., 1984; Ticknor and Vandergraaf, 1986; Ticknor et al., 1989; Ticknor et al., 199I).

On the whole, the obtained data confirm that adsorption onto fracture walls strongly reduced the total potential for mass-transport of radionuclides under consideration (usually $\mathrm{R} \gg>1)$.

In the natural geochemical systems the retardaction factor (or the distribution coefficient) is not a constant but depends on numerous hydrochemical interactions in the liquid as well as in the solid phase within the contamination plumes. That explains the errors of predictions of the pollutant's fate in aquifers using distribution coefficients determine under idealized laboratory conditions which differ from the field one. Similar errors occur when hydrogeochemical conditions are variable (as it occurs during remediation measures carried out to restore groundwater quality in polluted sites).

The mentioned alteration in the RNT potential in the multi-component systems can be caused by complexation reactions and sorption of the radionuclides on mobile colloidal particles (Section 4) in the liquid phase.

Formaly speaking, the role of all of these interactions should be taken into consideration by numerical algorithms for the multicomponent transport problem, but in many cases such numerical approach would not be supported by the available thermodynamic data. Although many authors are very sceptical about the Kd-concept it is difficult to deny the 
important advantages of this approach for the description of solute transport in heterogeneous groundwater reservoirs. In this situation the analytical approach or onecomponent simulation implicitly including homogeneous (in liquid phase) interactions into linear parameters of traditional equations might be preferable in comparison with multicomponent models.

\section{Appendix 2}

\section{Some generalized solutions for mass-transport in fractured-porous reservoirs}

Let's consider the general problem of subsurface transport of a decaing substance in fractured-porous reservoir. If the assumption of the "Representative Elemental Volume" (REV) is valid the advective-dispersion equation, the differential form can be writ- ten as follows:

$$
n \frac{\partial C}{\partial t}+\lambda n C+w_{s}=L(C)
$$

where $n$ is the active fractured porosity (relative volume of fractures); $\lambda$ is the decay constant; $L(C)=n D \nabla^{2}(C)-v \nabla(C) ; D$ is the dispersion coefficient, $v$ is the Darcy velocity.

The function $w_{s}$ reflects the solute diffusion from fracture water into the porous matrix as well as decay within the latter. The analytical representation of the $w_{s}$ - function depends on the mathematical and physical conceptualization of the transport process within the porous matrix and should be connected with the time and space frames of it (Mironenko and Rumynin,1980). Two practically important approximations have been suggested

$$
w_{s}=\sqrt{\lambda_{m}}[\sqrt{\lambda}(\operatorname{erfc} \sqrt{\lambda t}-1)-\exp (-\lambda t) / \sqrt{\pi t}] \cdot C
$$

- it is often referred to as the "unlimited capacity" approximation,

$$
w_{s}=n_{0} \frac{\partial C_{b}}{\partial t}, \quad \frac{\partial C_{b}}{\partial t}=\alpha_{m}\left(C-C_{b}\right)-\lambda C_{b}
$$

- can be referred to as the "quasi-steady state" approximation; 
here $C$ and $C_{b}$ are solute concentrations in fractured and porous water, $\mathrm{n}$ is the matrix porosity, $\lambda_{m}$ and $\alpha_{m}$ are the complex mass-exchange parameters $\left(\lambda_{m}=S_{b} D_{M} n_{0}^{2}, \quad \alpha_{m}=\lambda_{m} / n_{0}^{2} . S_{b}\right.$ is the specific surface of the matrix blocks, $D_{M}$ is the coefficient of molecular diffusion).

The general solution of the equation (A.2) can be represented as (Rumynin, 1983):

$$
C=\int_{0}^{t} \frac{\partial C^{\prime}(\theta)}{\partial \theta} H_{0}(t, \theta) d \theta
$$

where $C^{\prime}(\theta)$ is a solution describing stable component transport in equivalent homogeneous media,

$$
H_{0}(t, \theta)=L^{-1}\left\{\frac{1}{p} \exp \left(-\frac{G_{p} \theta}{n}+\lambda \theta\right)\right\}_{p \rightarrow t-\theta}
$$

$L^{-1}$ symbolizes the inverse Laplace transformation; $G_{p}$ is some function of the complex argument $\mathrm{p}$ :

$$
G_{p}=\sqrt{\lambda_{m}(p+\lambda)}
$$

- for the unlimited capacity approximation, and

$$
G_{p}=\frac{\lambda_{m} n_{0}}{p+\lambda_{m}+\lambda} \cdot p
$$

- for the quasi-steady state approximation.

Thus for the basic approximations we found:

1)

$$
H_{0}(t, \theta)=\frac{1}{2} \exp (-\lambda \theta)\left[\exp (-\eta) \operatorname{erfc}\left(\frac{\eta}{2 \sqrt{\tau}}\right)+\right]
$$

$$
+\frac{1}{2} \exp (-\lambda \theta)\left[\exp (\eta) \operatorname{erfc}\left(\frac{\eta}{2 \sqrt{\tau}}+\sqrt{\tau}\right)\right]
$$

$\left(\tau=\lambda(t-\theta), \quad \eta=\theta \sqrt{\lambda \lambda_{m}} / n\right)$

2) $H_{0}(t, \theta)=\exp (-\eta)\left[\exp (-\tau) J_{0}(2 \sqrt{\eta \tau})+\int_{0}^{\tau} e^{-z} J_{0}(2 \sqrt{\eta z}) d z\right]$

$\left(\tau=\gamma(t-\theta), \quad \eta=\beta \theta, \quad \gamma=\alpha_{m}+\lambda, \quad \beta=\alpha_{m} n_{0} / n, \quad J_{0}(\right.$.$) - ordinary Bessel function).$ 
It is easy to notice that substitution of into $t_{f}\left(t_{f}\right.$ is the residece - time for particles traveling along arbitrary stream-lines) in formulae (A.9) and (A.10) leads to the wellknown solutions (for the dimensionless function $\mathrm{C}$ ) obtained under the assumption of solutes transport in fractures with a sharp interfaces (Tang et al.,1981).

Further formula (A.10) can be transformed such that

$$
C=H_{0}\left(t, t_{f}\right)=\exp \left(-\lambda t_{f}\right) J(\tau, \eta)
$$

where $J(\tau, \eta)=1-\exp (-\tau) \int_{0}^{\eta} e^{-z} I_{0}(2 \sqrt{\tau z}) d z$ is a well-known function describing transport of stable components in fractured-porous media $\left[\tau=\alpha_{m}\left(t-t_{f}\right), \quad \eta=\alpha_{m} t_{f} n_{0} / n\right]$ (Mironenko and Rumynin, 1986). Therefore:

$$
C_{\lambda>0}=\exp \left(-\lambda t_{f}\right) C_{\lambda=0} \quad\left[\tau \rightarrow \tau^{\prime}=\left(\alpha_{m}+\lambda\right)\left(t-t_{f}\right)\right]
$$

The other expression for solution (A.5) can be obtained in the form:

$$
C=C^{\prime}(\theta) H_{0}(t, \theta)_{0}^{t}-\int_{0}^{t} C^{\prime}(\theta) \frac{\partial H_{0}(t, \theta)}{\partial \theta} d \theta .
$$

For example for a quasi-steady state approximation we get

$$
\begin{gathered}
\frac{\partial H_{0}(t, \theta)}{\partial \theta}=-\exp (-(\eta+\tau))\left[\beta I_{0}(2 \sqrt{\eta \tau})+\gamma \sqrt{\eta / \tau} I_{1}(2 \sqrt{\eta \tau})\right] \\
C^{\prime}(\theta) H_{0}(t, \theta)_{0}^{t}=C^{\prime}(t) \exp (-\beta)
\end{gathered}
$$

In the particular case for solute transport in homogeneous groundwater reservoir we have:

$$
C=C^{\prime}(t) \exp (-\lambda t)+\lambda \int_{0}^{t} C^{\prime}(\theta) \exp (-\lambda \theta) d \theta
$$

If the component decays simultaneously in the contaminant source (A.13) is transformed into

$$
C=C^{\prime}(t) \exp (-\lambda t) \text {. }
$$


Appendix 3

\section{A brief overview of the performed hydrogeological assessment for hypothetical accidents at industrial and experimental nuclear reactors in Russia}

Several new nuclear power plants are planned to be built in Russia. Among them the Kola (in the third stage), the Far-East and the St.-Petersburg (a new extension project) plants are under construction. Simultaneously geological exploration takes place within these areas. This Section presents some preliminary results associated with problems of hydro-geoenvironmental substantiation of the designed stations.

1. Kola nuclear power station. The construction site of the station is located within the lake lowland, being framed by a chain of low hills (foothills of the Khibini Mountains) and by the Imandra lake (Rumynin et al., 1993). Fractured granite-gneiss rocks of homogeneous type (porosity of matrix is less then $1 \%$ ) serve as the major reservoir for groundwater. This produces preconditions for rapid propagation of pollutants within the aquifer. The high vulnerability of the lake water is explained by the small distance (no more than $1 \mathrm{~km}$ ) from the reactor compartment - a potential source of contamination - to a shore line - the boundary of underground flow discharge.

The presence of active flow through fractures was confirmed by a specific series of hydrogeological investigations within the key sites (Table A.1) including: a) tracer $(\mathrm{NaCl})$ injection during multi-well pumping tests; b) isotope (J-131) injection into the natural gradient water flow; c) well dilution technique. The results of the different methods are in good agreement; in particular, they showed that the flow velocity (U) ranges from 0.8 to $3.6 \mathrm{~m} /$ day and the relative fracture volume $\mathrm{n}=0.001-0.004$

The data obtained were used for the verification of a numerical two-dimensional model of mass-transport (on the basis of the MOC code by Konikov and Bredehoeft, 1985). This code was supplemented by analytical subroutine to take into account radioactive decay (see Section 3 and Appendix 2).

The first stage of this model construction - its flow substantiation - was associated with an identification of the permeability field; for this purpose an inverse flow problem was solved. The reliability of these results seems to be rather high taking into account the 
Table A.1. Characteristics of convective transport

\begin{tabular}{|c|c|c|c|}
\hline Site & $\begin{array}{l}\text { Groundwater } \\
\text { velocity } \\
\text { (U), m*day }{ }^{-1} \star\end{array}$ & $\begin{array}{l}\text { Darcy } \\
\text { velocity } \\
(\mathrm{V}), \mathrm{m} \times \mathrm{day}^{-1} \times x\end{array}$ & $\begin{array}{l}\text { Active porosity } \\
\text { (relative volume } \\
\text { of fractures) } \\
(n) \star x\end{array}$ \\
\hline $\begin{array}{l}1 \text {-Special } \\
\text { housing } \\
\text { N2-Reactor } \\
\text { compartment }\end{array}$ & $\begin{array}{l}0.8-1.2 \\
2.0-3.6\end{array}$ & $\begin{array}{l}0.001-0.002 \\
0.001-0.02\end{array}$ & $\begin{array}{l}2.4 E(-3) \\
1.5 E(-3)\end{array}$ \\
\hline
\end{tabular}

Note:

* - Isotope $\left({ }^{131} \mathrm{~J}\right)$ injection under natural gradient flow condition;

*x - Well-dilution technique;

$x * x$ - Injection of salt tracer ( $\mathrm{NaCl}$ ) into piezometers during multi-well tests. 
increased density of flow monitoring network. This conclusion is confirmed by a good agreement of the velocity distribution obtained on the model and by direct field measurements.

Therefore, the relative fracture volume may be directly used for predicting ground water contamination by the chemically non-reactive radionuclide J-131. The corresponding results for the first pathway of radioactivity release have shown that in spite of the high rates of mass-transport, the rapid decay of the radionuclide facilitates the decrease of concentrations essentially below the Safety Standard Concentration (Fig.A.3).

The transport velocity of the other radionuclides (e.g.Cs-137, Sr-90, Ce-144) depends on their sorption onto the fracture walls. The laboratory tests indicated the average value of the constant $K_{a}=1 \mathrm{~cm}$ to be typical for these three isotopes (Fig.A.2). Hence the average value of $\mathrm{R}=100$ which was determined using the specific surface of blocks $\left(S_{b}\right)$ ranging from 0.1 to $0.2 \mathrm{~cm}^{-1}$.

Despite the great sorption retardation for long-living radionuclides a complete autoepuration of groundwater from radioactive contamination will not occur because of the very high concentration at the contaminant source in case of the first pathway of radionuclides release: residual concentrations within the area of flow discharge into the lake exceed permissible values by several orders of magnitude (Fig.A.4). However, the long duration of contaminant migration allows to rely on a timely realization of the necessary measures for protective drainage.

One can note an uncertainty in the performed evaluation of the retardation factor because of the potential errors in the determination of $S_{b}$. This requires performing further investigations based a the probabilistic analysis.

2. The Far-East nuclear power station. Major reservoirs of groundwater within this region are represented by fractured-porous strata (sandstones and siltstones). The site is located within the catchment at a distance of about $3 \mathrm{~km}$ from the river, where the flow discharge takes place (Fig.A.5). Such a combination of conditions - heterogeneity of the medium and long paths of migration - produce the favourable conditions for efficient self-cleaning of groundwater under influence of sorption and radioactive decay. 


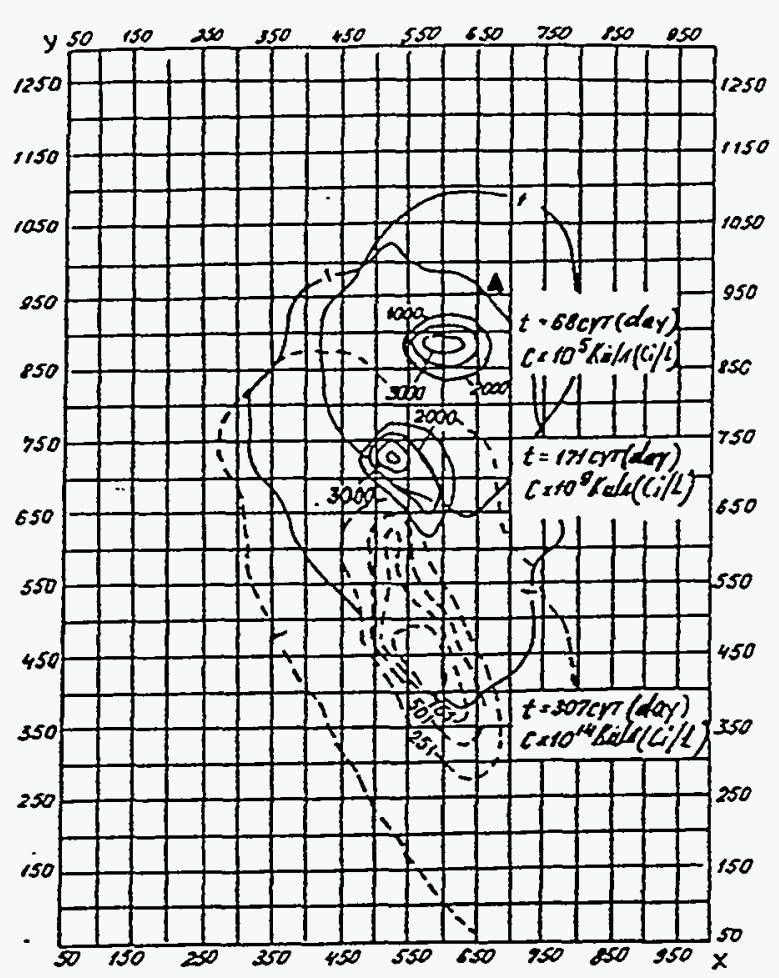

Fig.A.3. Contaminant plume (I-131) formed in the aquifer after a hypothetical accident at the Kola NNP

(low boundary of the model corresponds to the lake-shore line)

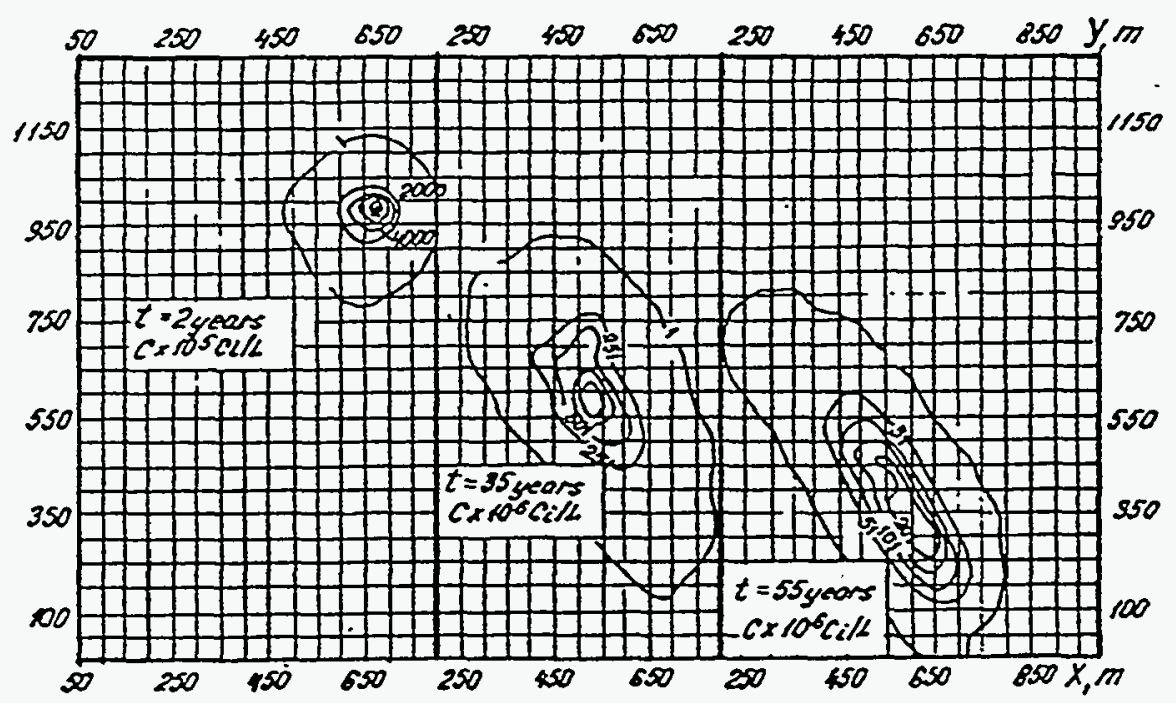

Fig.A.4. Contaminant plume (Sr-90) formed in the aquifer after a hypothetical accident at the Kola NPP 
The possibility for an active role of these processes in a porous matrix was proved by laboratory experiments establishing rather high values of a molecular diffusion coefficient $\left(n_{0} D_{M}=2.2 \cdot 10^{-7}-2.1 \cdot 10^{-6} \mathrm{~m}^{2} d^{-1}\right.$ while porosity no is up to $8 \%$ ). The intrablock sorption could be described by the minimum values of the adsorption distribution coefficient as follows: $K_{d}=0.8 \mathrm{~cm}^{3} \mathrm{~g}^{-1}$ for $S r-90$ and $K_{d}=1.3 \mathrm{~cm}^{3} \mathrm{~g}^{-1}$ for $C s-137$. The conclusions on the extent of groundwater protection from radionuclides contamination was based on the regional transport model. A particular case is shown in Fig.A.5.

For solving the inverse flow problem data from the groundwater monitoring were used. Suitable distribution on the model of "megaheterogeneity" zones within the area under study satisfactorily agree on the whole with the results of multi-well and slug pumping tests. At the same time it is evident that such a regional approach provides a rather high degree of averaging for aquifer flow properties over the area and in the cross section, which is not always permissible when considerating mass-transport problems (Mironenko and Rumynin, 1980). Indeed, within the probable plume of contamination there could be local zones (due to tectonic jointing ) with sharply increased permeability. However, they do not necessarily manifest themselves on the regional potentiometric surface map, information which has been obtained by a rather sparse network of piezometers. Meanwhile precisely these zones could be the principal carries of contaminants.

This kind of uncertainty was partially eliminated by detailed electric sounding. In combination with the study of drilled core material, it allowed detect ion within the construction site of the plant of at least two zones with different fracturing intensity. In principle, the relation between the permeability of these zones may vary over a wide range of values, however, it is limited by the value of the average permeability, obtained from the solution of the inverse problem on a regional scale. Thus such additional information has provided a background for further multivariant sensitivity analyses.

3. The St.-Petersburg Nuclear Power Plant (a new stage of construction). A geological cross section is represented by stratified granular (porous) deposits. According to the project nuclear reactors will be located at distance of about $1 \mathrm{~km}$ from the Finland Gulf where a regional groundwater flow discharges. Modelling techniques were similar to the previous example. Interpretation of field data obtained in a neighbouring wastes disposal 


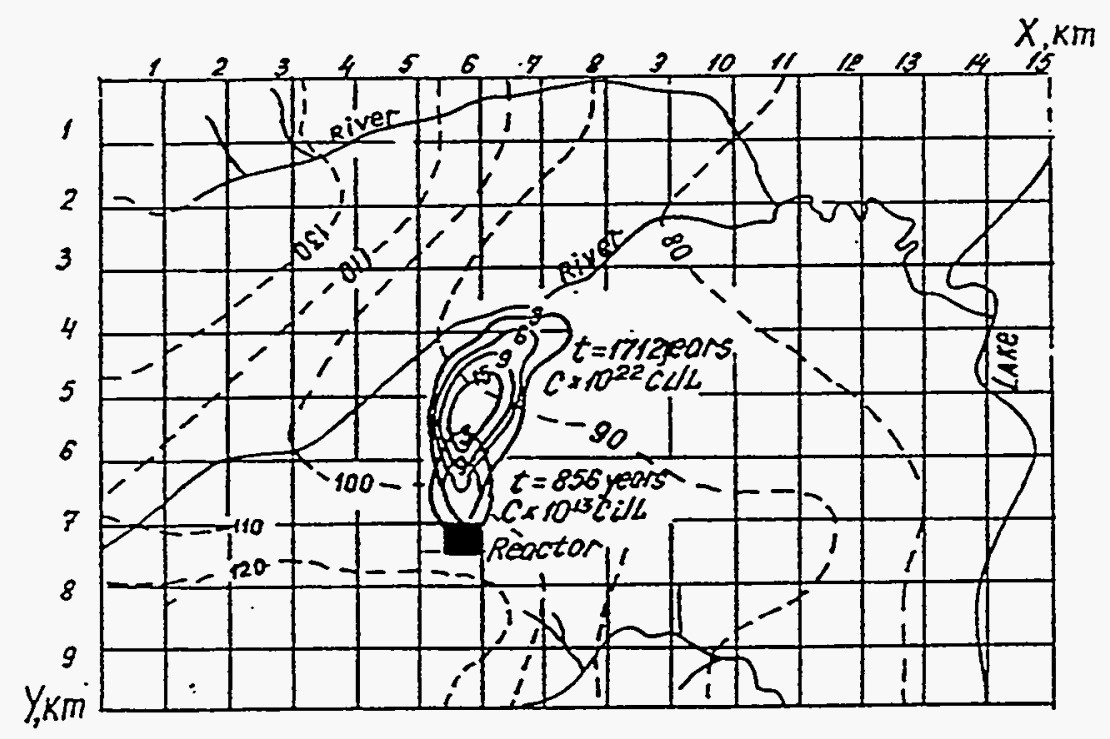

Fig.A.5. Contaminant plume (Cs-137) formed in the aquifer after a hypothetical accident at the Far East NPP 
site under operation (about $0.5 \mathrm{~km}$ apart) enabled to increase the reliability of the forecasting. On that site one of the largest surface repositories of radioactive wastes in the North-West part of Russia is situated. A plume formed in the phreatic aquifer moves down the natural flow gradient. It is characterized by a rather complex nuclide composition. Detected concentration distribution of individual species within the plume show different retardation parameters. Having numerically solved the inverse migration problem we managed to determine some hydrogeological parameters which were used for the assessment of the consequences of hypothetical accidents at the designed nuclear plant.

\section{Appendix 4}

\section{Surface complexation}

The surface complexation models are described in detail in a number of earlier publications. The models postulate that the water molecules and chemical dissolved species form bonds with the exposed lattice-bound ions at mineral surfaces (Van Cappelenet et al., 1993). The primary hydratation surface sites are treated as hydroxylated surfaces ation centers: >SOH, where > symbolizes the mineral lattice and $\mathrm{S}$ is the mineralization.

The surface hydroxyl group of the $>\mathrm{SOH}$ site can be deprotonated $\left(>\mathrm{SO}^{-}\right)$or protonated $\left(>\mathrm{SOH}_{2}^{+}\right)$. The relevant reactions are controlled by the $\mathrm{pH}$ of the solution. Dissolved cations and anions may specifically adsorb at the interface by exchange with $\mathrm{H}^{+}$or $\mathrm{OH}^{-}$at $>\mathrm{SOH}$ surface sites.

Two surface-complexation models are included in SURFEQL's modular:" constantcapacitance (CCM) and triple-layer (TLM) models.

In CCM adsorption all components is characterized by a surface potential $\Psi_{0}$, hence:

$$
[i]_{s}=[i] \exp \left(-\frac{z F \Psi_{0}}{k T}\right)
$$

the subscript "s" refers to surface concentration, $Z$ is the charge of the surface complex, F is Faraday's constant $(96486 \mathrm{C} / \mathrm{mol})$. The potential can be defined from the relation

$$
\Psi_{0}=\frac{\delta}{c},
$$


where $c$ is the capacitance (in $\mathfrak{I m}^{-2}$ ) of the electric double layer, and is the surface charge (in $\mathrm{Cm}^{-2}$ ). The parameter $\delta$ could be calculated by means of a special iteration procedure via total surface component concetration and the specific surface area $S_{\mathcal{S}}\left(m^{2} \cdot d m^{-3}\right)$. Thus, three interactive parameters must be entered: the capacitance ( $c$, in $\mathfrak{S m}^{-2}$ ), the solid surface area ( $S_{A}$, in $\left.m^{2} g^{-1}\right)$, and the solid concentration, or solid-to-water mass ratio $\left(C_{S}, g L^{-1}\right)$. Hence $S_{S}=S_{A} C_{s} / n$ ( $n$ is the porosity).

For the TLM, the inner layer contains the adsorbed $\mathrm{H}^{+}$and $\mathrm{OH}^{-}$, and is characterized by the potential $\Psi_{1}$. The outer layer contains all other adsorbed ions and is characterized by the potential:

$$
[i]_{s}=[i] \exp \left(-\frac{z F \Psi_{1}}{k T}\right),
$$

For mathematical convenience, the second term in both models equations (A.17) and (A.18) is formally treated as a electrostatic component with a concentration $\exp \left(-\frac{z F \Psi_{i}}{k T}\right)$. 